Article

\title{
Augmented Virtuality for Coastal Management: A Holistic Use of In Situ and Remote Sensing for Large Scale Definition of Coastal Dynamics
}

\author{
Sandro Bartolini ${ }^{1}$, Alessandro Mecocci ${ }^{1}$, Alessandro Pozzebon ${ }^{1, *} \mathbb{1}$, Claudia Zoppetti ${ }^{1}$, \\ Duccio Bertoni ${ }^{2}$ (D), Giovanni Sarti ${ }^{2}$, Andrea Caiti ${ }^{3,4}$, Riccardo Costanzi ${ }^{3,4}{ }^{(1)}$, Filippo Catani ${ }^{5}$ (D), \\ Andrea Ciampalini ${ }^{2,5}$ (D) and Sandro Moretti ${ }^{5}$ \\ 1 Department of Information Engineering and Mathematical Sciences, University of Siena, Via Roma 56, \\ 53100 Siena, Italy; bartolini@dii.unisi.it (S.B.); alemecoc@alice.it (A.M.); claudia.zoppetti@gmail.com (C.Z.) \\ 2 Department of Earth Sciences, University of Pisa, Via Santa Maria 53, 56126 Pisa, Italy; \\ duccio.bertoni@for.unipi.it (D.B.); sarti@dst.unipi.it (G.S.); andrea.ciampalini@unipi.it (A.Ci.) \\ 3 Department of Information Engineering, University of Pisa, Via Girolamo Caruso 16, 56122 Pisa, Italy; \\ andrea.caiti@dsea.unipi.it (A.Ca.); riccardo.costanzi@unipi.it (R.C.) \\ 4 Research Center "E.Piaggio", ISME-Interuniversity Research Center on Integrated Systems for the Marine \\ Environment, Largo Lucio Lazzarino 1, 56122 Pisa, Italy \\ 5 Department of Earth Sciences, University of Florence, Via Giorgio La Pira 4, 50121 Firenze, Italy; \\ filippo.catani@unifi.it (F.C.); sandro.moretti@unifi.it (S.M.) \\ * Correspondence: alessandro.pozzebon@unisi.it; Tel.: +39-349-424-5468
}

Received: 10 January 2018; Accepted: 7 March 2018; Published: 11 March 2018

\begin{abstract}
In this paper, the authors describe the architecture of a multidisciplinary data acquisition and visualization platform devoted to the management of coastal environments. The platform integrates heterogeneous data acquisition sub-systems that can be roughly divided into two main categories: remote sensing systems and in situ sensing systems. Remote sensing solutions that are going to be implemented include aerial and underwater data acquisition while in situ sensing solutions include the use of Radio Frequency IDentification (RFID) tracers, Wireless Sensor Networks and imaging techniques. All the data collected by these subsystems are stored, integrated and fused on a single platform that is also in charge of data visualization and analysis. This last task is carried out according to the paradigm of Augmented Virtuality that foresees the augmentation of a virtually reconstructed environment with data collected in the real world. The described solution proposes a novel holistic approach where different disciplines concur, with different data acquisition techniques, to a large scale definition of coastal dynamics, in order to better describe and face the coastal erosion phenomenon. The overall framework has been conceived by the so-called Team COSTE, a joint research team between the Universities of Pisa, Siena and Florence.
\end{abstract}

Keywords: coastal monitoring; remote sensing; in situ sensing; augmented virtuality; AUV; drones; RFID; Wireless Sensor Networks; 3D imaging

\section{Introduction}

The preservation of coastal areas is a major challenge that any administration has to deal with in the new millennium. Coastal areas are paramount for several reasons, spanning from economic factors to naturalistic aspects. For instance, the economy of many littoral territories is based on tourism (e.g., beach resorts, restoration, leisure activities) or port activities (e.g., commerce, industries, tourism); environmental features, such as dunes, sea fauna and flora, also draw the attention of dedicated tourism, not to mention the importance of the naturalistic value. Coastal erosion has been a worldwide issue since the Eighties [1], affecting more than $70 \%$ of sandy coasts, and this percentage has never 
decreased. It is a complex process, characterized by the interaction of a variety of different factors: for instance, it can be either more or less intense locally along the very same beach. In general terms, the erosion processes are triggered by a significant decrease in river bedload transport rates: the sediments do not reach the sea and the littoral currents, once responsible for the longshore distribution of the river sediments to feed the adjacent beaches, begin to entrain the grains that already constitute the beaches [2]. The sediments would shift according to the direction of the littoral drift, but they would not be replaced. Progressively, the updrift sector of the beach would be eroded, whereas the downdrift sector might experience accretion unless the sediments are lost offshore. The factors that may induce river bedload reduction include changes in land use, the proliferation of hard embankments covering the river banks and dams hampering the sediment movement towards the coast, the extensive quarrying of the riverbed, and also the protection of mountain slopes from hydrological processes, which reduce soil erosion and the production of loose sediments [3]. Not only human-related activities along the river catchment contribute to worsening the erosion processes, at least at the local scale: for instance, port structures such as piers or seawalls interrupt the natural longshore distribution of sediments, leading to updrift accretion and downdrift erosion at either sides of the structure. Sometimes breakwaters and groynes that were built to protect the beach might end up intensifying the erosive drive as well as port structures. Erosion effects are also magnified by progressive sea level rise [4,5]. This factor has opened up relevant debates about the chance to either protect specific sectors of the coast or let the system free to evolve without anthropic interventions in accordance with the "managed retreat" concept [6]. While the former is more appropriate to sites where human settlements are well-established, the latter is increasingly applied to natural coastal areas. Managed retreat is not an option in densely populated countries, where low-lying beaches, often connected to large deltaic complexes, are subjected to multi-hazard threats determined by climatic change, whose most critical effect on coastlines is sea-level rise. As a matter of fact, worldwide many studies already addressed this issue, which might potentially become a serious social concern, analyzing the coastal vulnerability by means of ad hoc indices [7-9] or remote sensing techniques [10,11].

In the past decades, coastal erosion issues were often addressed with the realization of hard protection structures (e.g., groynes, breakwaters, seawalls) to counteract the erosion effect. The so-called "hard approach" [12] was not intended to solve, nor to reduce, the primary factors responsible for the erosion processes, but rather to fix an apparent equilibrium state of a specific sector of the coast by confining the sediments within the very same sector. While this approach may work locally despite the unpleasant visual impact of the structures that leads to a deterioration of the landscape, sometimes it does not take into full account the consequences on the adjacent sectors of the coast. The transmission of the erosion effects downdrift is a major shortcoming of these protection schemes, which basically need in-depth investigations prior to the construction and frequent monitoring afterwards. Based on the double-edged efficacy of this approach, projects requiring the utilization of hard structures potentially affecting local morphodynamics were preferably discarded and replaced by operations intended to artificially restore the suffering sectors of coast. Beach feeding activities, or replenishments, generally constitute the so-called "soft approach" [12]. As replenishments involve the input of additional sediment volumes into a starving system, often softer approaches are favorably accepted by decision-makers and the communities. Nonetheless, they are far from being considered the ultimate solution. As a matter of fact, beach feeding does not come cheap and needs frequent integrations because sediments would keep on being displaced according to the direction of the littoral drift; in addition, strong attention must be paid to textural and morphometric parameters of the filling sediments, as compatibility with the native sediments should be maintained as far as possible to extend the durability of the intervention and to avoid environmental issues; finally, they are still intended to fix a local problem rather than act on the primary causes.

Therefore, the concept that needs to permeate any layer, from the decision-makers to the stakeholders, from the private citizens to the scientists, is to start thinking of the coastal system at a larger scale, from the drainage basin to the sea along an imaginary cross-shore transect, and also in 
terms of physiographic unit along the coast. A wise and effective coastal management depends on a strong and influential governance that might be able to cross the administrative limits, thus allowing for considering the erosion issue in terms of littoral cells and no more just locally.

The first step is to accept a paradigm shift: the evolution of the coastal environment is not just affected by the processes acting along the shoreline, but also on the drainage basin and along river courses. The transversal scale (the well-known "source-to-sink" approach) needs to be taken into full consideration because a paramount question still without a clear answer is how much sediment is delivered by rivers to the coast, and, as a consequence, how much of this sediment is further displaced offshore to a depth where no process is able to bring it back to the beach-two questions in need of urgent response because no evaluation of sediment budget can ever be made without quantitative answers to these burning questions. Nonetheless, the longitudinal scale must be addressed in terms of physiographic unit: too often, the beaches have been managed locally, without considering the consequences that these kinds of interventions may have on adjacent coastal sectors. A wise plan to counteract the erosion effects and to a further extent to manage the coastlines includes a proper redistribution of the sand, which must not depend on the administrative limits of municipalities. It is imperative that the redistribution of sediments from accreting areas to retreating areas via either by-passing or back-passing has to be managed without any interference due to city limits. In all this, the collaboration between any social layer should be particularly stressed: sharing knowledge and setting up actions involving universities, local governments, stakeholders, professionals, schools, and the communities as a whole must be the focal point to make conscious decisions in accordance with the precautionary approach and to efficiently counteract the erosion issue along any coast.

In this context, this paper presents a novel conceptual approach aimed at addressing the problem of coastal erosion within the scale and the framework described before. This approach is based on the concept of multidisciplinarity and holism, where different scientific fields, from earth sciences to marine sciences and engineering make available in a cooperative way their expertise as well as their techniques and technologies. Similarly, the concept of shared knowledge is presented, describing the information interchange between academics, administrations and citizens that can be established through the proposed Augmented Virtuality paradigm: the presented platform is open toward the inputs received by different actors but is at the same time a showcase, available and browsable by everyone, in a full bi-directional data exchange. In order to present such a complex ecosystem, the paper addresses the concept of multidisciplinarity as a whole, exploring the possible techniques and technologies to be integrated and focusing on the description of the conceptual architecture of the Augmented Virtuality platform.

This paper is structured as follows: Section 2 focuses on the importance of the holistic approach for coastal management, describing how cooperation between different disciplines is crucial for a 360-degree data acquisition on coastal phenomena. Sections 3 and 4 are devoted to the presentation of a base set of different techniques and instruments that are currently expected to be employed in data collection for the proposed platform: these include all the knowledge currently available in the working team. Additional techniques and instruments (for example Global Navigation Satellite System (GNSS) signal reflectometry, terrestrial Mobile Mapping, current and wave meters) have not been cited in the paper because, at the moment, they are not present among the skills of the working team, but are expected to be added in the next future according to the open and inclusive approach of the proposed solution. Regarding the description of the techniques, Section 3 is devoted to remote sensing techniques that are currently employed or expected to be used for remote data acquisition, while Section 4 focuses on in situ sensing techniques. Section 5 describes the proposed Augmented Virtuality visualization paradigm and the overall data acquisition and management architecture. Finally, Section 6 presents some concluding remarks. 


\section{A Holistic Approach for Coastal Management}

The coastal environment is usually defined by the dunes, the beach and the nearshore. In that sense, the coastal system is just a tight strip, almost negligible relative to the width of other environments. Nonetheless, several processes acting on the coasts are strictly connected to the adjacent systems: as already pointed out, coastal erosion shows its effects along the shore, but many of its causes have to be looked for in river catchments. Likewise, the sediments that are entrained by the wave motion and distributed elsewhere by the currents might accumulate beyond the surf zone. Therefore, it is crucial for any study concerning the coastal system to take into account all the processes acting on the other environments because their effects also spread along the coast. This notion is not as common as it should be, mainly due to the complexity to deal with so many different factors coming from so many different settings and, very likely, in so many different timespans.

Similarly, coastal erosion is basically a geological process, being the result of complex interactions between coastal geomorphology and several hydrodynamic factors (e.g., waves, tides, surges). Nevertheless, a wide range of critical factors can be listed both as collateral causes and as possible mitigating solutions. For example, the chemical composition of seawater and its interaction with beach sediments, especially on artificial coarse-clastic beaches, may end up in corrosive processes that could eventually lead to a remarkable volume loss (preliminary laboratory tests performed on marble samples collected from artificial beaches along the Tuscany coast point out that mass loss due to sea water-sediment interaction is not negligible), while the presence of specific vegetation species may have a positive effect in slowing down the erosive process on dunes. This means that the cooperation between different scientific disciplines is crucial for a broader in-depth comprehension of the erosion phenomena: according to [13], a multidisciplinary approach would be then the perfect starting point to gain immediate benefits in terms of coastal management. Coastal morphodynamics, river supply processes, sedimentology, geomorphology, applied geology, hydrogeology, biology, coastal engineering, robotics, remote sensing, positioning and navigation are the most significant disciplines that contribute to this holistic approach: nevertheless, also knowledge coming from farther scientific sectors like economy, management or law may have a crucial role in tackling specific issues.

The holistic approach is also paramount for the development and improvement of the techniques and technologies employed in the data collection, storage and elaboration activities. Each of the disciplines listed above contributes with its own methodologies to the creation of datasets that can be fused with the other ones to create a large amount of heterogeneous information. One of the main goals of the proposed framework is to provide each scientific field with innovative technological instruments coming from its joint work with experts coming from the Information and Communication Technologies (ICT) sector. In Sections 3 and 4, a list of mature and innovative technological solutions, which can be applied for data collection in different scientific fields and from different points of view, is presented. These solutions allow for defining the coastal erosion phenomenon at different scales and with different approaches: each technique is then complementary to the others and concurs in defining a global overview of the morphological processes. Transversal to all the techniques is data acquisition and elaboration: each collected dataset can be either individually analyzed or fused with other datasets to obtain higher levels of abstraction. Complementary to the data acquisition process is the last brick of the proposed framework: data visualization. Information needs to be available to a wide range of users: not only scientists have to analyze the data, but also common citizens may be interested in consulting high level information. This means that knowledge in the field of interaction design and 3D imaging are also required for this final step.

The holistic approach for coastal management has already been discussed-for example in [14], but real implementations can be hardly found in marine monitoring systems. Some online coastal data navigation tools can be found in different parts of the world. Among them, it is possible to cite in the USA the Coastwide Reference Monitoring System (https:/ / www.lacoast.gov/crms2/Home.aspx), that collects data regarding the wetlands in the state of Louisiana, and the Delaware Coastal Flood Monitoring System (http:/ / coastal-flood.udel.edu), which provides information about flood risk in 
the coastal areas of the state of Delaware. Outside the USA, it is possible to cite the Web portal of the UK Environment Agency (https:/ / www.gov.uk/government/organisations/environment-agency), which provides datasets from different environmental domains, including coastal areas, and the Coastal Management Information System (CMIS-http: / 45.79.129.215/index.html) of the state of Karnataka, India, providing different interaction modalities. Anyway, all these systems are mainly Geographic Information Systems (GIS) with a very low level of interaction and a monodisciplinary approach. One interesting example is the European Multidisciplinary Seafloor and Water-column Observatory (EMSO) [15]: this European-scale infrastructure deals with the collection and analysis of heterogeneous marine data, with an approach similar to the one proposed in this paper, but in a larger scale. While this approach may be useful to manage large amount of data coming from an entire continent, the system presented in this paper has been envisioned to work at best within a definite sector of the coast, which usually should correspond to a physiographic unit. A physiographic unit is defined as a portion of a coast that has no sedimentary exchange with the adjacent sectors: sediment input only comes from river discharge or cliffs, and can only be lost offshore. In that regard, such system may represent the best option to process and interpret the data in order to provide useful suggestions to protect the coastal area and improve its management. Another interesting data management infrastructure is the Digital Coast platform, developed by the US National Oceanographic and Atmospheric Administration (NOAA) (https:/ / coast.noaa.gov/digitalcoast/), which provides a wide range of tools to access a large quantity of heterogeneous data about seas and oceans. Nevertheless, this platform lacks a ready-to-use 3D navigation tool based on the Augmented Virtuality paradigm as the one proposed in this paper. This makes the platform very useful to scientists and experts but hardly usable by private citizens. Moreover, the Digital Coast platform lacks a crowdsourcing approach that may become crucial for the creation of large, participative datasets. Some solutions have focused on the multidisciplinary approach only in regards to the instrumentation [16] and the methodologies $[17,18]$, without widening the scale of the monitoring infrastructure. As far as we know, such a comprehensive approach as the one proposed in this paper has never been discussed before.

\section{Remote Data Acquisition}

\subsection{Proximal and Distal Remote Sensing}

Since the 1970s, remote sensing techniques and products have been used to monitor the evolution of coastal zones. Today, remote sensing techniques represent inexpensive and fast methods to obtain a huge amount of data over wide areas and/or very specific information. Coastal studies can benefit from the use of very different sensors. Proximal and remote sensing can be used in combination in order to obtain data from different point of views. For example, the hyperspectral portable spectroradiometer, which operates at a distance of a few centimeters from the sample, has been used to retrieve information about grain size, mineralogical composition [19], surface moisture [20], and salinity [21] of coastal sediments from their spectral properties. The spectroradiometer measures reflectance in 3-10 nm bandwidths over the 350-2500 $\mathrm{nm}$ range. This sensor can be used both directly on the field or in laboratory under controlled conditions. Proximal sensors allow obtaining a huge amount of punctual information about physic-chemical information of the materials, which form the coastline (sand, silt, rocks). This information can be profitably used to produce thematic maps interpolating the obtained results. Considering other available ground based sensors, coastal studies can also benefit from the use of the Terrestrial Laser Scanner (TLS), which is able to produce a dense point cloud that can be used to build a 3D model of a selected area. This technique is particularly useful to monitor the stability of coastal cliffs or coastal structures (e.g., harbors, defense structures) affected by erosion [22] at the toe acquiring point clouds in different periods (e.g., before and after a storm or seasonally). In fact, this technique allows measuring ground $3 \mathrm{D}$ temporal displacements by comparing sequential datasets of the same scenario. 
The monitoring of coastal cliffs and/or coastal slopes [23,24] can also be achieved using a Ground Based interferometer (GB-InSAR), which is a computer-controlled microwave transceiver equipped with a moving antenna capable of synthesizing a linear aperture along the azimuth direction. The system can acquire Synthetic Aperture Radar (SAR) image each around $1 \mathrm{~min}$. The phase difference between images (interferogram) acquired in different moments are used to produce displacement maps. The GB-InSAR operates at a distance typically less than $3 \mathrm{~km}$, thus it can be used to monitor the deformation of a relatively small area. This technique can also be used to monitor the deformation of man-made coastal structures. Moving far from the target, another useful technique is represented by the Digital Photogrammetry (DP) by means of Unmanned Aerial Vehicles (UAV). DP is a well-established technique for acquiring dense 3D geometric information from stereoscopic images acquired in sequence by a calibrated digital camera [25]. This technique can provide both very high resolution optical images ( $5 \mathrm{~cm}$ of spatial resolution) and high resolution Digital Elevation Models $(0.05 \mathrm{~m} / \mathrm{pix})$ of a study area [26]. Multiple acquisitions over time can be used to monitor the morphological evolution of the area of interest over time.

The above-mentioned sensors and technologies need specific acquisition campaigns and allow acquiring information on relatively small areas. In order to carry out a complete study by means of a holistic approach, which includes not only a wide sector of coast but also the inland sector, we need for sensors to be able to cover very wide areas. Airborne and satellite remote sensing imagery can help to retrieve data over wider areas with respect to ground-based sensors. Optical and SAR sensors are commonly used to study and monitor the landscape evolution $[25,27,28]$. Optical imagery represents low cost and/or freely-available products extensively used to monitor the coastal environment [19,27,29-34]. Space-borne multispectral sensors (e.g., Landsat 8 and Sentinel-2) are considered powerful tools for the identification and mapping of coastal geomorphological features and changes. Despite their lower spatial resolution (e.g., $30 \mathrm{~m}$ for Landsat and $10 \mathrm{~m}$ for Sentinel-2), they can be profitably used instead of high-cost, Very High Resolution (VHR) airborne or commercial satellite imagery. The main advantage of multispectral imagery is given by the acquisition through different spectral bands of the electromagnetic spectrum and the capability to perform multi-temporal analysis. The former advantage is commonly used to map chemical and physical characteristics of sediments and rocks, to evaluate water turbidity [35,36], identify currents [19], and detect pollutants or algal bloom [37]. The multi-temporal analysis helps to measure major changes in coastline [38-40].

At the same time, SAR images can be used to obtain information on the coastal environment. SAR is an active sensor that uses microwaves which are based on the same technology of the GB-InSAR described above but mounted on satellite. Microwaves are transmitted from the sensor, backscattered from targets located at the ground and received again by the sensor. The received signal is then transformed into a grey-scale image. The main advantage of these kinds of sensors with respect to the optical ones is represented by the possibility to acquire images in all-weather conditions and also during the night. Today, the most important sensor is represented by the new mission Sentinel-1 composed by two satellites that acquire images each six days.

The single SAR image can be used to automatically extract the coastline, thus, by using a set of images acquired in different periods, it is possible to monitor the coastline evolution [41,42]. Each SAR image is composed of pixels characterized by a value of amplitude and phase. The latter can be used to measure ground displacement using at least two SAR images $[43,44]$. The multi-temporal interferometric techniques (MIT) are based on the analysis of a stack of coregistered SAR imagery [45] processed by means of different algorithms (e.g., Permanent Scatterers Interferometry, PSInSAR [46-48]). These techniques allow measuring the deformation of coherent radar targets (Permanent Scatterers, PS) along the Line of Sight (LOS) of the sensor, with millimetric accuracy and with respect to a stable point. MIT techniques can be applied from regional to local scale detecting ground deformation occurred during a specific time interval detecting coastal subsidence $[28,49]$ and slope instability of high coasts [50]. The PSI technique can fail in the case of wide sandy beaches because of the high backscattering of the radar signal due to the terrain roughness. The problem can 
be partially solved using the SqueeSAR technique [39], which allows the measurement of ground deformation by using point-wise coherent scatterers (PS) and partially coherent Distributed Scatterers (DS). Coastal subsidence can be detected not only along the coastline but also several kilometers inland, especially in the case of coastal plains where sediments compaction can provoke regional subsidence. Benchmarks or local permanent references are needed for an accurate georeferencing of point clouds obtained through both the TLS system and drone survey. Reference points are also useful for PSI analysis. Despite the limited number of measurable points that can be acquired in the same period with respect to PSI and TLS systems, Global Navigation Satellite System (GNSS) positioning (based on Network or traditional Real Time Kinematic) is the most accurate positioning technique [51]. In order to improve the spatial accuracy of the TLS, drone and PSI measurements, the GNSS positioning will be used to establish control points.

The aforementioned techniques can be fruitfully integrated to characterize the coastal environment and its evolution at different scales, from local to regional, and in time reconstructing changes of the coastal morphology and of the environmental characteristics (vegetation, pollution, turbidity, etc.). Results produced using proximal and distal remote sensing techniques will be represented by thematic maps as the one shown in Figure 1 (i.e., grain size, mineralogy, ground deformation, elevation) and maps of coastal evolution (i.e., change in the coastline, land cover changes). These maps will feed the Coastal Management (CosMan) system representing a sort of zero reference epoch at the beginning of the project and its temporal evolution over time.

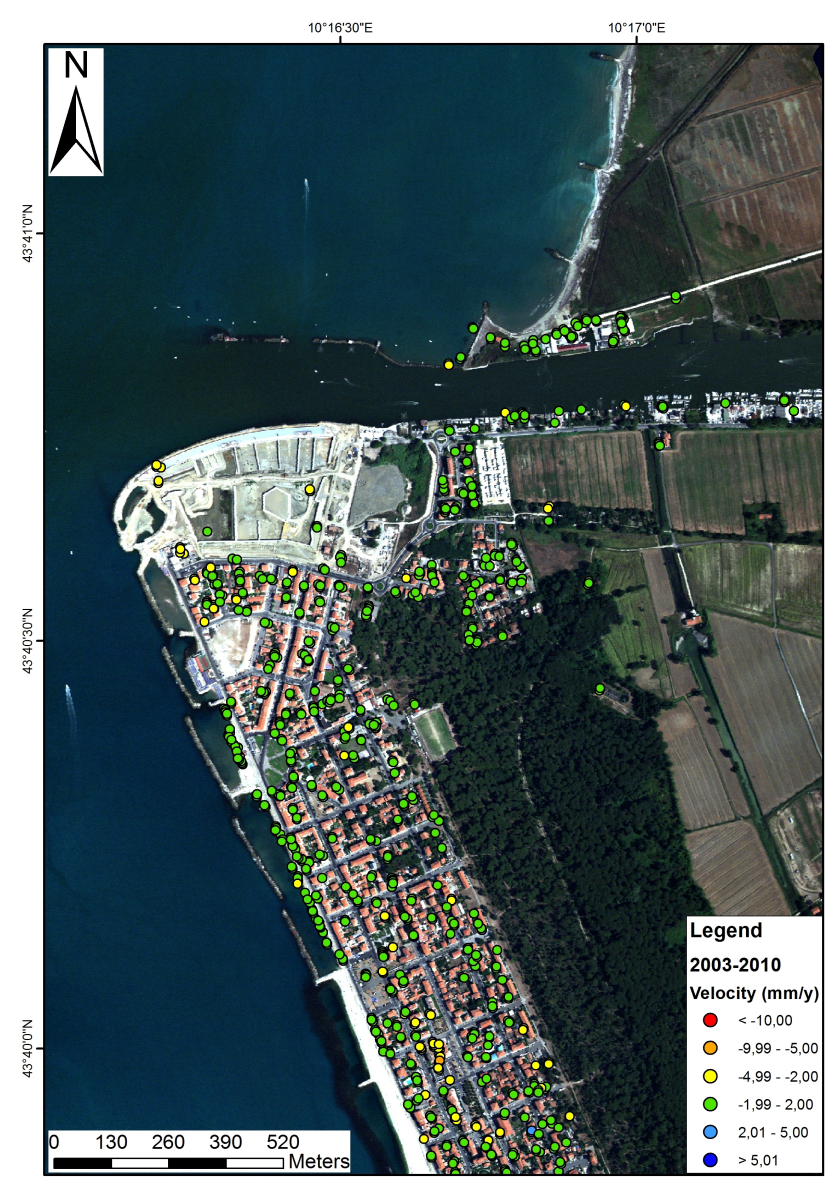

Figure 1. Ground deformation velocity map obtained using Envisat Synthetic Aperture Radar (SAR) data (period 2003-2010) on a true color image in RGB mode $(8,5,2)$ of the study area acquired using the airborne multispectral sensor Daedalus. 


\subsection{Underwater Remote Sensing Techniques}

The possibility of exploiting advanced remote sensing technologies plays a fundamental role also for the collection of data from the submerged part of the coastal area. Information about the morphology of the sea bottom within the target area and about its modification during the time is precious to understand the dynamics of the analyzed coastal system. Underwater Robots, in particular Autonomous Underwater Vehicles (AUVs), represent the ideal tool to perform the necessary tasks of this activity limiting or totally avoiding the presence of human operators in the water, with immediate positive consequences in terms of safety.

Different examples of bathymetric surveys carried out by means of commercial AUVs are reported in the literature, including several shallow water applications. They are based both on small size AUVs (e.g., REMUS 100 [52,53]) and large size ones (e.g., HUGIN in [54]). At the same time, AUV technology became mature and reliable enough in the last years to guarantee advantageous operational costs and associated mission time, turning to be the convenient choice for a wide range of different applications. AUV technology is then expected to be extensively and systematically employed for activities of sea bottom mapping and monitoring. DII (Department of Information Engineering) of the University of Pisa (UNIPI) collaborated in recent years in projects that, among their goals, had the development of AUVs. The main result in this sense is the outcome of the regional (Tuscany) project THESAURUS (http:/ / thesaurus.isti.cnr.it/): a dyad of $300 \mathrm{~m}$ rated AUV prototypes-respectively named TifOne (Figure 2) and TifTwo (Tifone class)—were produced, for underwater archaeology applications, in the framework of a collaboration between the University of Pisa and the Department of Industrial Engineering of the University of Florence (DIEF-UNIFI)—both of them ISME (http:/ / www.isme.unige. it/) nodes. AUVs in general, and Tifone class AUVs in particular, are thought to be vector vehicles for the transportation on the target area of the desired payload sensors [55].

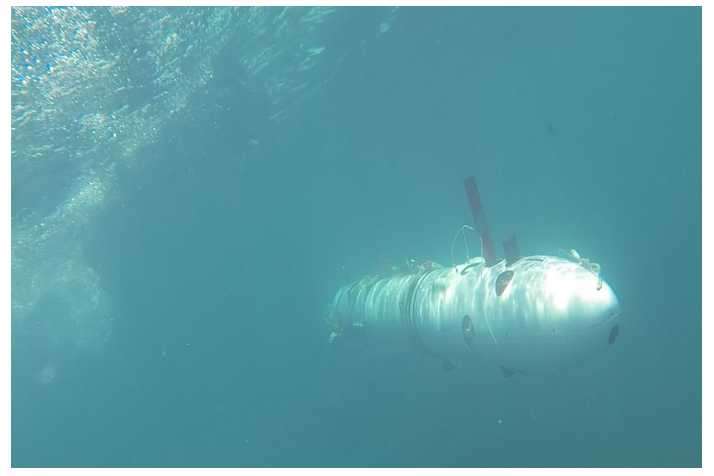

Figure 2. TifOne Autonomous Underwater Vehicle (AUV) performing a survey mission.

From the maneuverability point of view, AUVs like Tifone class ones can manage to navigate very close to the shore thanks to their redundant actuation along the different degrees of freedom.

AUVs are then expected to periodically cover the submerged area of the target coastal system with acoustic sensors suitable of providing a set of information including, according to the necessity, bathymetry, morphology or stratigraphy. Through the analysis of the data collected by means of the AUVs and their integration with all the information from all the different sensor systems adopted and described in this work, it will be possible to understand the local dynamics of volume shifts under nominal conditions and, potentially, as a consequence of extraordinary phenomena. Acoustic devices that could provide significant information about the dynamics of the coastal system and that could be integrated on AUVs as payload sensors are: 
- Side Scan Sonar (SSS): this sensor allows for covering wide areas in a brief amount of time, the information that can be extracted from SSS data is a rough bathymetry in addition to the morphology of the sea bottom;

- Bathymetric Multi Beam EchoSounder (MBES): this sensor provides a detailed (measurements of the seabed elevation are determined with a down to centimeter resolution) representation of the sea bottom profile suitable for 3D reconstruction as e.g., Digital Elevation Model (DEM);

- Sub Bottom Profiler (SBP): this sensor is a low frequency sonar that emits acoustic waves capable of penetrating the sea bottom and of interpreting the echo coming from the first meters to discriminate the nature of the different stratigraphic layers.

All the named sensors are commercially available in versions suitable for their integration on a limited size vehicle (as e.g., AUVs). After their acquisition, payload data are integrated with the navigation state estimation for an absolute georeferencing: this is one of the most critical aspects of the processing chain. The resulting geographical position of the payload measurements are affected by an error that can be even up to few tens of meters according to the quality of the available sensor set for georeferencing. This is mainly due to the impossibility of using the GNSS when the vehicle is underwater. Alternative solutions have to be adopted. This problem is strongly studied within the scientific community and recently led to related reference surveys (e.g., [56,57]). A considerable effort in last years was dedicated by the authors to the problem of AUV localization and, consequently, payload data georeferencing, mainly working on two complementary lines:

- Estimation based on proprioceptive data: methods, mainly based on the Kalman filter approach, for the fusion of proprioceptive sensor (e.g., DVL_Doppler Velocity Log, AHRS-Attitude and Heading Reference Systems) signals and dynamic evolution knowledge, have been investigated and experimentally validated [58].

- Estimation aided by acoustic systems: strategies based on measurements of relative distance and/or direction of the AUV with respect to a set of a priori known or unknown acoustic nodes [59]. This includes also cooperative localization strategies based on relative measurements between different AUVs and on communication of synthetic navigation data [60].

Navigation systems exploiting both of the approaches could reach very low errors on the estimated position: down to few meters of error with respect to the GNSS signal assumed as ground truth [61].

\section{In Situ Sensing}

In situ sensing techniques to be applied can be summarized based on three main categories:

- RFID and tracking technologies,

- Wireless Sensor Networks,

- Video Monitoring.

Nevertheless, possible additional technological assets are expected to be integrated in the next future.

\subsection{RFID and Tracking Technologies}

The tracking of sediments is of key importance to define coastal and fluvial dynamics. Different techniques have been studied in the last decades to study the movement of both sand $[62,63]$ and pebbles $[64,65]$. While sand movements cannot be studied tracking every single grain, punctual tracing can be achieved on coarse-grained beaches. Regarding sand beaches, the most common tracing technique is based on the use of fluorescent tracers [66], while some cases exist where magnetic and radioactive tracers have been employed [67]. To our knowledge, no technique currently exists based on the use of real-time ICT solutions. A wider range of solutions exists for coarse-grained beaches. In this case, while the techniques listed for sand beaches have been employed, painted tracers have also been widely used. Moreover, some solutions also exploit Radio technologies [68]. 
In this context, the CosMan framework is expected to integrate different tracing techniques, with a specific focus on a technique named "Smart Pebble" [69,70]. This technique is based on the use of Low Frequency RFID transponders embedded inside common pebbles collected directly on the beach under study. The pebbles are holed using a common drill, a transponder is glued on the bottom, and then the hole is sealed. Three different typologies of transponders can be used: $35 \mathrm{~mm}$ disc tags, $32 \mathrm{~mm}$ glass cylinders and $12 \mathrm{~mm}$ glass cylinders [71]: according to the different typology of transponders, pebbles of varying dimensions and shapes can be traced.

The tracing operations follow this procedure:

- The tagged pebble (the so-called Smart Pebble) is positioned on the beach in a specific position, according to a pre-defined scheme;

- Following the positioning, the exact position of the Smart Pebble is recorded by means of an Real Time Kinematic - Differential GPS (RTK-DGPS) instrument, whose horizontal and vertical accuracy is about $1 \mathrm{~cm}$, and associated with the ID of the embedded transponder;

- After a pre-defined span of time, the Smart Pebble is localized and identified by reading the ID of the transponder through an ad hoc waterproof RFID reader that is employed as a sort of metal detector to perform a full scanning of the beach;

- The new position of the Smart Pebble is recorded;

- The Smart Pebble can be either left on site to go on with the tracking or recovered to perform morphometric analysis.

Such a technique allows the sediment tracking for both the emerged and the submerged portions of the beach: underwater pebbles are usually recovered in the nearshore at depths hardly over $2 \mathrm{~m}$. The underwater operator can easily hold the pole of the instrument and record the position. Both the Smart Pebbles and the reader have been designed to be waterproof, and the operating frequency $(125 \mathrm{kHz}$ ) allows a long range (up to $60 \mathrm{~cm}$ ) underwater data transmission (a Smart Pebble and the reader can be seen in Figure 3.). Different typologies of experiments can be set up: short term $(6,24$ and $48 \mathrm{~h})$ tracking experiments, long term tracking experiments $(1,2$ months up to 1 year) and morphometric experiments where together with the position, also morphometric data about the pebble (weight, shape, roundness) are recorded. All the data collected by the Smart Pebble sub-system are made available to the CosMan platform as a collection of datasets: each dataset keeps the pebble ID and the $x, y$ and $t$ values identifying the position of the pebble at a specific time. Additional fields in the dataset are used for the morphometric data.

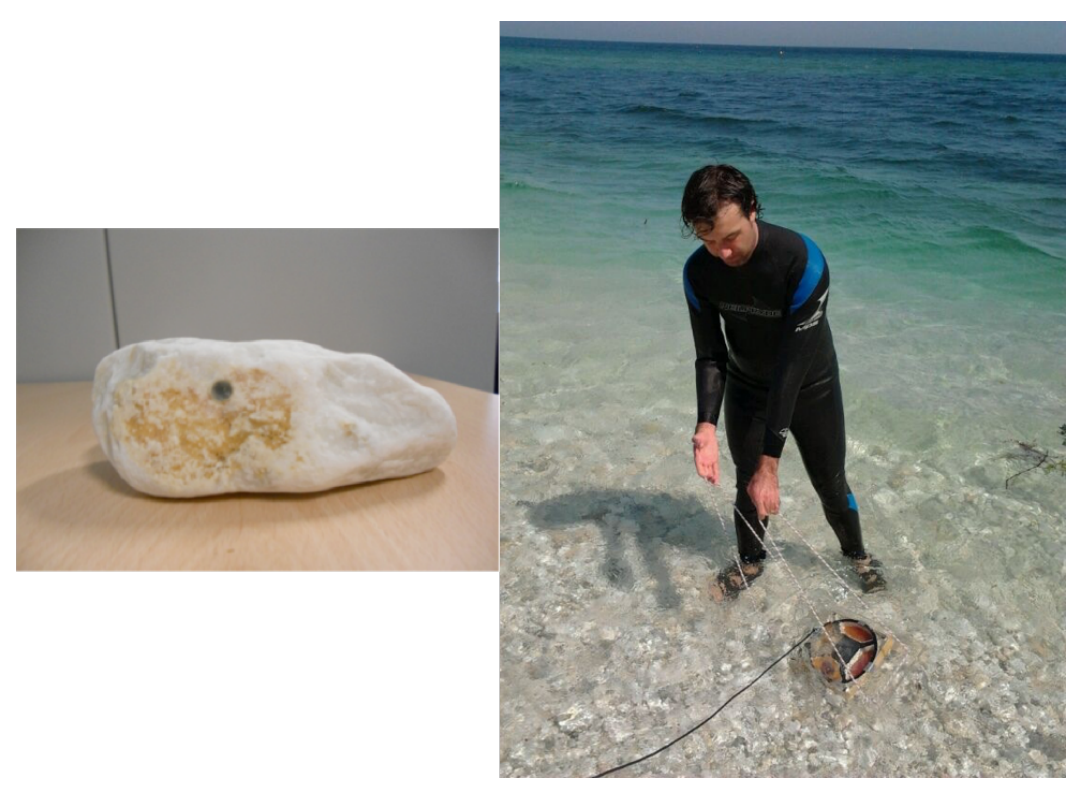

Figure 3. A Smart Pebble and a moment of the pebble localization operations. 


\subsection{Wireless Sensor Networks}

Wireless Sensor Networks (WSN) are widely employed for environmental monitoring: in [72] several solutions in different contexts are presented. WSNs have also been employed for the monitoring of coastal and marine environments [73,74]. Nevertheless, most of the applications focus on the analysis of water quality and are based on the use of floating devices. Several examples of Underwater Sensor Networks can also be found [75]. Indeed, only few solutions focus on the analysis of coastal dynamics.

In this framework, WSN are expected to be employed for several purposes, among them:

- Analysis of coastal morphodynamics for sandy beaches;

- Analysis of bedload and suspended sediment transport;

- Monitoring of marine weather and marine parameters;

- Monitoring of water quality;

- Measurement of river sediment discharge into the sea.

Regarding the CosMan ecosystem, three different WSN architectures are expected to be employed, according to the three different segments of the area under study: Beach WSNs, Marine WSNs and Fluvial WSNs. Regarding the Beach segment, WSNs are expected to be integrated in the CosMan architecture to analyze the beach morphodynamics [76]. The structures will integrate different kinds of Wireless Sensor Nodes, in charge of collecting different data typologies, which, if fused, allow for estimating remotely and in real time the sand transport in a sample portion of a beach. These Nodes include Sand Level Sensor Nodes in charge of measuring in real-time height variations of the sand level, in order to dynamically assess the morphological variations, Sand Collector Sensor Nodes in charge of measuring in real-time the amount of sand transported by the wind and thus to assess the dynamic behavior of the sand layer, and Environmental Sensor Nodes, collecting atmospheric data and thus allowing to correlate data about the transported sand, with information about winds and weather (see Figure 4).

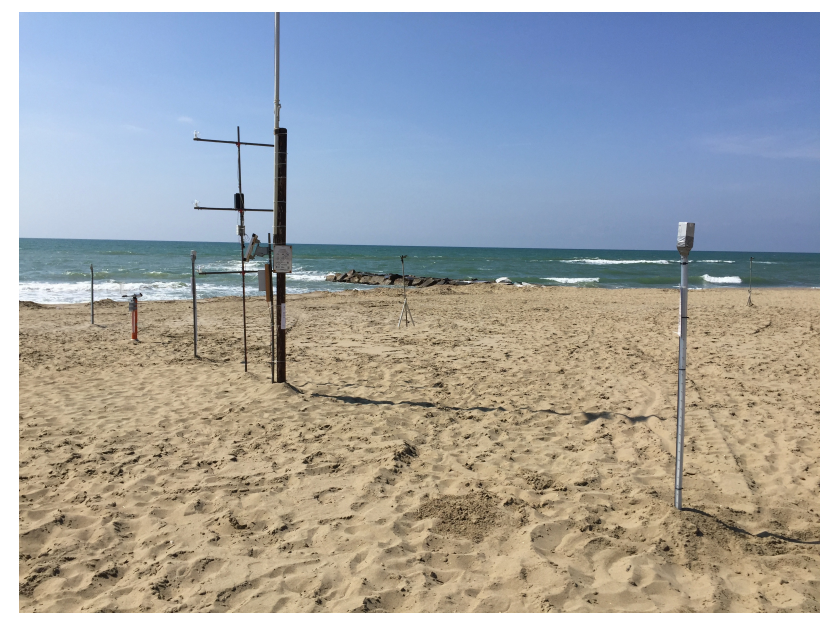

Figure 4. A deployed Beach Wireless Sensor Network (WSN).

The Marine WSNs are expected to be composed of a set of Sensor Nodes to be positioned in the near-shore portion of sea. Each Sensor Node is expected to include wavemeters and current meters as well as Sand Trap structures to analyze the seabed sediment transport. While the sensing devices are expected to be positioned close to the seabed, they will be linked to floating structures housing data acquisition, elaboration and transmission modules. These WSNs are also expected to integrate floating sensing vehicles in charge of analyzing water quality parameters, thus developing a network architecture composed by fixed and mobile Sensor Nodes.

The Fluvial WSNs aim at studying the sediment transport. In this case, the main issue is the calculation of the sediment transport, concerning both bed load and suspended sediments. The proposed 
structures are expected to be employed for short spans of time (ranging from a few hours to some days) and will integrate two different typologies of Sensor Nodes: Suspended Sediment Sensor Nodes and Bed Load Sensor Nodes. Suspended Sediment Sensor Nodes are basically densimeters provided with network connection: these nodes are also expected to integrate Water Flow Sensors in order to calculate the effective hourly sediment transport rate. Bed Load Sensor Nodes are under study and will be based on a principle similar to the one applied to Sand Collector Sensor Nodes.

All these WSNs will be locally based on either ZigBee or LPWAN (LoRa) connection, according to the specific network requirements, and will rely on a Cloud infrastructure for remote data acquisition: this will allow the data post directly on the CosMan platform. Each dataset provided to the CosMan platform will be made available according to a standard data format including the collected numeric values, the position of the sensor node and a timestamp.

\subsection{Video Monitoring}

The use of video cameras for in situ coastal management has become a valuable system [77], in order to perform ship traffic and tourist flow control. Video cameras can also be used for monitoring the coastal evolution, from an in situ perspective, eventually integrated with other sensing systems dedicated to the same purpose. These systems often provide a "unified" type of data that can be processed to extract meaningful statistics related to the shoreline mutations. For example, time-exposure (or timex) images have been the primary output product of the Argus protocol: each image represents the mathematical time-mean of all acquired frames computed over a fixed interval of time. In these "pictures", moving objects, as well as waves, are averaged so that is possible to visualize their fluctuations as bright pixels in the timex images. The peculiarity of time-exposure images is then the delineation of areas where wave breaking occurs as a white stripe. Similar to the mathematical time-mean representation, there is also the variance image, where pixels associated to moving objects have higher values in the image dynamic range.

\subsubsection{Acquisition Systems}

In the following, a short list of popular surveillance and monitoring system found in literature is presented (for range, resolution, frequency of acquisition and other features of these system, please refer to Table 1):

- The Argus Video system ([A] -http://www.planetargus.com/). The Argus video system is the first system based on video acquisition for coastal monitoring and it is considered a standard. It has been especially implemented for the coastline change detection on a long-term basis exploiting timex images analysis [78,79].

The system typically consists of four to five cameras, with a total coverage of 180 degrees of HFOV (Horizontal Field Of View). The snapshot image, time exposure image and the variance image are usually collected every hour, with ten minutes of exposure time for the last two types of data. The accuracy of the measurements on the shoreline evolution has been assessed through comparison with DGPS (Differential Global Positioning System) results, leading to $0.35-2.4 \mathrm{~m}$ in cross-shore and 10-20 $\mathrm{m}$ in altimetry.

- The EVS Video system system ([B]-Erdman Video Systems-http://video-monitoring.com/). The EVS system is based on high resolution digital camera acquisition and a web-based fruition and manipulation of these resources: in fact, the built-in video server integrated in the system allows to access the camera parameters (pan/tilt/zoom) as well as the image database. An example (installation of Terracina) has been reported in Table 1.

- The Beachkeeper video system ([C]-[80]). The image elaboration system of Beachkeeper is particularly valuable because it exploits the pre-installed webcams along the beaches, while it also consents to retrieve georeferenced and rectified images as well as the timex (mean and variance) images. Giving the variability of the composition of this system, it is hard to provide a general 
performance reference because any assessment on the accuracy depends on the single sensor characteristics. An example (Pietra Ligure installation) is reported in Table 1.

- The KOSTA Video system ([D]—www.kostasystem.com). KOSTA coastal video monitoring is based on a photogrammetric technique, which allows for transforming 2D image coordinates into the corresponding 3D real world coordinates [81]. This is an important feature because the 3D information provides a description of the acquired scene at a different level, introducing the possibility of performing metric measures on the data.Since 2006, three KOSTA systems have been installed (www.kostasystem.com): depending on the number of sensors, their resolution and their location, the monitored area and the quality of the video images are defined (see Table 1).

- The COSMOS System ([E]-[82]). The COSMOS system is based on the geometric correction of the acquired images followed by the feature extraction (e.g., timex and variance images). Another important characteristic of this system is the fact that it is designed to work with any type of camera, providing to the final users a flexible platform in terms of installation constraints. Various sites, especially in Portugal, employ a COSMOS installation, for various purposes (coastline evolution, beach nourishment evolution, wave breaking patterns, etc.. In order to estimate the accuracy, comparison with 30 Ground Control Points (GCP) is reported.

From the above-mentioned systems [A], [B], [C], [D], [E], it results that few efforts in processing the beach data have been pushed, in terms of degree of automation and then rendering. The systems presented provide macro features of the monitored site (e.g., the automatically extracted shoreline) only in some cases, while in most cases the automatic processing they are equipped with is mainly applied for the geometric correction or for the orthorectification of the acquired data. The output visual rendering is therefore often made up of the orthorectified and georeferenced image, in order to provide the user with an overview of the monitored site. This type of output, however, has a spatial resolution that is not always optimal, varying with respect to the distance from the sensor. Moreover, if the shoreline was also provided (even superimposed on the orthorectified output), this is typically obtained from timex images, so that the temporal resolution of these systems is not very high.

\subsubsection{Shoreline Change Detection for Coastal Monitoring}

In general, the term "change detection" is used to refer to those automatic processing techniques that provide a map of changes in the monitored context as output. The implementation of change detection frameworks for image (or video) systems typically means that changes are to be found in the temporal sequence of the acquired data, that is, a set of images or a stream video. For the context regarding the monitoring of the evolution of the coast, therefore, we will look for the changes in time of the shoreline itself, which will be extracted from each image/video frame, such as the variation of the position with respect to a previous instant or a fixed baseline. Then, the changed pixels will compose the output map, retrieved with the same spatial and temporal resolution of the input data. Depending on the processing data domain chosen and the implemented algorithms, the change detection framework (considered for video based systems) could benefit from better spatial and temporal resolution, and then increasing the availability of data for macro indicators evaluations. Moreover, following the change detection methods applied in SAR remote sensing, some principles can also be applied to the video based systems employed for coastal monitoring [78,83].

As introduced above for the systems reported in literature, timestack analysis can be useful to represent the changes of coastal features in time, especially related to the shoreline. The difficulty in the analysis of the variability in time of this feature is the fact that, depending on the duration of the interval of observation (short or long term analysis), different and ambiguous results can be obtained. Therefore, the detection interval must be chosen properly, in order to both reject rapid oscillations of sea backwash and retrieve the instantaneous water level. This is the main reason why the video based systems in literature provide timex images, which natively filter out rapid variations in the scene. In this way, it is possible to correctly model the shoreline behavior through isodepths, as defined in [84], but it requires an appropriate sizing of the phases of acquisition of the system. Temporal series 
of isodepths acquired during a tidal cycle allow to retrieve a three-dimensional representation of the beach. Timex images are also used to perform clustering on pixels in the HSV (Hue Saturation Value) domain to obtain the wet/dry segmentation and then retrieve the separating line, corresponding to the shoreline. In the last years, various techniques and composite systems of video acquisition have been employed in shoreline evolution monitoring. Terrain systems [85] are both costly and incapable of collecting data at the proper spatial and temporal resolution [86]. Alternative systems are more compact, easy to install and use fixed video imagery [87] in order to provide lower-cost continuous data at desired (spatial and temporal) resolution, but they can cover only limited areas of the beach [82]. To summarize, new video acquisition systems should be re-designed in order to improve both spatial and temporal resolution (possibly near real-time), while equipped with automatic shoreline change detection algorithms.

The recent advancements in hardware multi-processing and 3D stereo computer vision have triggered the diffusion of new Stereo devices for a range of applications. Stereo cameras acquire two overlapping images at the same instant, as the human vision system: this overlapping zone allows to measure the disparity between corresponding points in the two images. This disparity, computed in pixels, can be then rescaled in metric units to obtain the 3D map [88].

Stereo vision devices are advanced video systems, capable of recording frames as well as standard video cameras, but they continuously store (at least) two synchronized (in time) frames at each fixed instant of acquisition. The depth map, which provides 3D information on the scene, can be then obtained in real time, allowing for a constant monitoring rate. The resolution in time can be then highly improved, also allowing the application of 3D processing techniques in real time. From the depth map, the "point cloud" can be then computed, representing the formal 3D description of the objects in the scene [89]. Then, the key feature of stereo vision is that it can be used to locate an object in 3D space [90]. It can also give valuable information about that object (such as color, texture, and patterns that can be used by intelligent learning machines for classification).

An example of point cloud is reported in Figure 5. The acquisition system, as mentioned above, acquires two synchronized (in time) images and a stereo matching [90] is performed, in order to retrieve the affine transformation between the first and the second view. The stereo system is also previously calibrated "offline" with specific known targets (e.g., a chessboard or in general a target to be seen by the stereo couple with visible keypoints) to infer metric information into the stereo model function. After the stereo matching, the disparity image is obtained, which represents the displacement, expressed in pixels, of the second view from the first one. From the disparity map, the 2D point in the disparity image can be converted into 3D points through a triangulation formula.

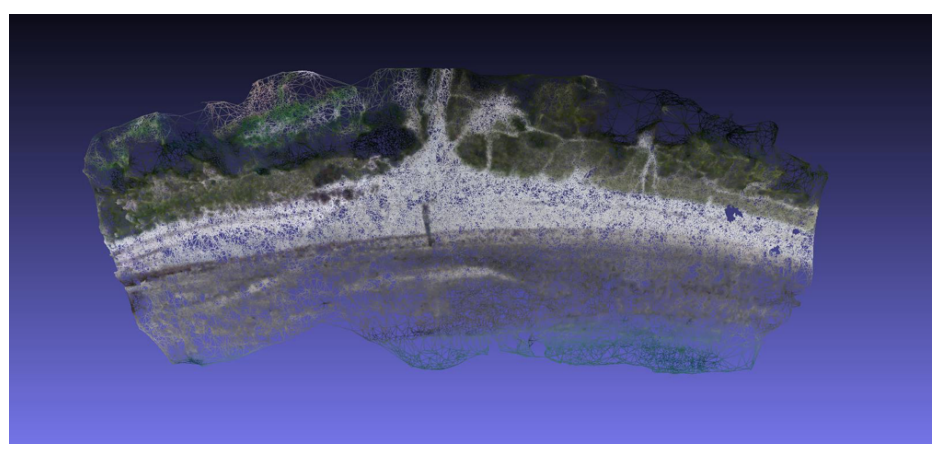

Figure 5. Point cloud of a portion of beach obtained through the proposed video processing techniques.

As reported in Table 1, the CosMan video sub-system is designed to process a different type of data, the RGB stereo couple, instead of a single image/frame: this is crucial because the shoreline (and other macro-indicators) extraction can be performed directly in the 3D domain. In fact, each vision module of the CosMan system can provide the disparity/depth image. These data can be then processed to extract the desired synthetic features and confer them to the fusion level. 
Table 1. Characteristics of the monitoring video systems. For each system, the following description is reported: (a) sensors employed (type and number, where available); (b) range (with respect to the sensor location); (c) frame rate of the system; (d) type of provided (processed) data; (e) resolution (referred to the sensor itself or other, if specified); (f) accuracy.

\begin{tabular}{|c|c|c|c|c|c|c|}
\hline Acquisition System & Sensor(s) & Range & Frame Rate & $\begin{array}{c}\text { Type of Processed } \\
\text { Data }\end{array}$ & Resolution & Accuracy \\
\hline ARGUS & $\begin{array}{l}\text { From } 4 \text { to } 5 \text { RGB } \\
\text { cameras }\end{array}$ & From $40 \mathrm{~m}$ up to $2.5 \mathrm{~km}$ & $\begin{array}{l}1 \mathrm{~h}(10 \text { min exposure } \\
\text { for timex and } \\
\text { variance images })\end{array}$ & $\begin{array}{l}\text { Snapshot- timex- } \\
\text { variance images + } \\
\text { rectified image }\end{array}$ & $\begin{array}{l}\text { (referred to the rectified } \\
\text { image) }-0.1 \mathrm{~m}(x, z), 0.5 \mathrm{~m}(y) \\
\text { at } 100 \mathrm{~m} \text { from the } \\
\text { station } / 0.5 \mathrm{~m}(x, z), 12.5 \mathrm{~m}(y) \\
\text { at } 1 \mathrm{~km} \text { from the station }\end{array}$ & $\begin{array}{l}\text { (Estimated with DGPS w.r.t. } \\
\mathrm{GCP}), 0.35-2.4 \mathrm{~m} \text { in cross } \\
\text { range, } 10-20 \mathrm{~m} \text { in } \\
\text { vertical range }\end{array}$ \\
\hline $\begin{array}{l}\text { EVS (ex. Terracina } \\
\text { installation) }\end{array}$ & $\begin{array}{l}\text { From } 4 \text { to } 5 \text { RGB } \\
\text { cameras }\end{array}$ & n.a. & $\begin{array}{l}5 \text { timex images } \\
\text { per day }\end{array}$ & $\begin{array}{l}\text { Snapshot- timex- } \\
\text { variance images + } \\
\text { rectified image }\end{array}$ & $\begin{array}{l}\text { (referred to the rectified } \\
\text { image) }-1.2 \mathrm{~m} \text { in cross } \\
\text { range- }-14 \mathrm{~m} \text { in along range }\end{array}$ & n.a. \\
\hline $\begin{array}{l}\text { BeachKeeper (ex. } \\
\text { Pietra Ligure } \\
\text { installation) }\end{array}$ & One webcamera & n.a. & 25 images $/ 30 \mathrm{~s}$ & $\begin{array}{l}\text { Snapshot- timex- } \\
\text { variance images + } \\
\text { rectified image }\end{array}$ & $\begin{array}{l}\text { depends on the single sensor } \\
\text { resolution characteristics }\end{array}$ & $\begin{array}{c}\text { (Estimated with DGPS w.r.t. } \\
\text { GCP) }-0.15-0.5 \mathrm{~m} \text { in cross } \\
\text { range }-0.55-2.9 \mathrm{~m} \text { in } \\
\text { along range }\end{array}$ \\
\hline $\begin{array}{l}\text { KOSTA (ex. Bakio } \\
\text { installation) }\end{array}$ & $\begin{array}{c}5 \text { RGB cameras } \\
\text { (16 mm lens }+4 \text { with } \\
12 \mathrm{~mm} \text { lens })\end{array}$ & n.a. & $\begin{array}{c}1 \text { hour (10 min } \\
\text { exposure for timex } \\
\text { and variance images) }\end{array}$ & $\begin{array}{l}\text { Snapshot- timex- } \\
\text { variance images + } \\
\text { rectified image }\end{array}$ & $\begin{array}{l}\text { (referred to the rectified } \\
\text { image) }-0.4 \mathrm{~m} \text { in cross } \\
\text { range }-5 \mathrm{~m} \text { in along range at } \\
1 \mathrm{~km} \text { from the station }\end{array}$ & n.a. \\
\hline $\begin{array}{l}\text { COSMOS (ex. Norte } \\
\text { Beach, Nazaré } \\
\text { installation) }\end{array}$ & $\begin{array}{l}\text { One MOTOBIX } \\
\text { camera at 3.1 Mpx }\end{array}$ & n.a. & n.a. & $\begin{array}{l}\text { Snapshot- timex- } \\
\text { variance images + } \\
\text { rectified image }\end{array}$ & $\begin{array}{l}\text { (referred to the rectified } \\
\text { image) }-0.1 \mathrm{~m}-10 \mathrm{~m} \text { in cross } \\
\text { range }-<2 \mathrm{~m} \text { in along range } \\
\text { at } 1 \mathrm{~km} \text { from the station }\end{array}$ & $\begin{array}{c}\text { (Estimated with DGPS w.r.t. } \\
\text { GCP)—rms }=1.18 \mathrm{~m} \text { in cross } \\
\text { range }-\mathrm{rms}=9.93 \mathrm{~m} \text { in } \\
\text { along range }\end{array}$ \\
\hline $\begin{array}{l}\text { CosMan (if ZEDcam } \\
\text { is employed) }\end{array}$ & $\begin{array}{l}\text { 4Mpx, } 1 / 3^{\prime \prime} \text { RGB } \\
\text { Stereo module }\end{array}$ & $\begin{array}{c}\text { From } 0.5 \mathrm{~m} \text { up to } 20 \mathrm{~m} \\
\text { (Depth range with } 12 \mathrm{~cm} \\
\text { of baseline) }\end{array}$ & From 15 up to $100 \mathrm{fps}$ & $\begin{array}{l}\text { Disparity- depth } \\
\text { image }+3 \mathrm{D} \text { point } \\
\text { cloud }\end{array}$ & $\begin{array}{c}\text { From WVGA up to } \\
2.2 \mathrm{~K} \text {-depth resolution is the } \\
\text { same as the video resolution }\end{array}$ & n.a. \\
\hline $\begin{array}{l}\text { CosMan (if arbitrary } \\
\text { RGB sensor is used } \\
\text { with arbitrary } \\
\text { baseline) }\end{array}$ & $\begin{array}{l}\text { Arbitrary resolution } \\
\text { and focal length }\end{array}$ & $\begin{array}{l}\text { From } 5 \mathrm{~m} \text { up to } 1 \mathrm{~km} \\
\text { (Depth range with } \\
\geq 90 \mathrm{~cm} \text { and } \leq 1.5 \mathrm{~m} \text { of } \\
\text { baseline) }\end{array}$ & From 15 up to $30 \mathrm{fps}$ & $\begin{array}{l}\text { Disparity- depth } \\
\text { image }+3 \mathrm{D} \text { point } \\
\text { cloud }\end{array}$ & $\begin{array}{l}\text { Depth resolution is the same } \\
\text { as the video resolution }\end{array}$ & n.a. \\
\hline
\end{tabular}




\section{Data Fusion and Augmented Virtuality}

\subsection{Overall System Architecture}

The implementation of a Coastal Management (CosMan) system through data acquisition and fusion, as well as Augmented Virtuality representation, requires a tailored ICT (Information Communication Technology) system architecture able to integrate a number of heterogeneous functionalities and technologies. Major features of the system can be summarized in the following macro-requirements:

- Ability to manage (feed (in), storing, elaboration, distribution to users and/or other systems (out) ) of heterogeneous data with high flexibility and interoperability with different systems and technologies;

- Management of data with georeferenced and time-referenced features;

- Advanced capability of data elaboration, fusion, 3D, as well as modularity of the software design in order to effectively re-use software components (i.e., I/O interface, elaboration) across specific data items, from existing libraries and effectively compose them together for fusion and related time/space elaborations.

In particular, there is profound variability in the interesting data feeds of this domain: for example in their intrinsic nature and software format, in the way they are (a) physically collected from the field (e.g., automatically, semi-supervised, supervised); (b) transmitted to the management system (e.g., directly and immediately through a telecommunication link, directly but when a link is, or is made, available). Other facets of each data feed are their timing and geo-localization, as well as the possible frequency in their sampling, when their collection and transmission can be automated. Table 2 exemplifies some data that we have considered as a reference for designing a flexible software architecture able to comply with their variability and with the need to analyze, fuse and elaborate them for the overall objectives of this project.

Undoubtedly, such data expose a high degree of variability and we have verified that a system able to cope with these is able to potentially manage, with zero or minimal adaptations, a wide range of other data that are typically collected on the field.

Lastly, a number of auxiliary data feeds are envisioned in this project and they do not necessarily aim to directly measure some physical properties of the coastal entities, or their evolution over time. We planned to provide some input channels to informal, and also social, data collection fluxes directly contributed by citizens to enrich the coastal status monitoring over time. Dually, some specific Augmented Virtuality views and services can be made public also to encourage the use of end-user applications and promote feeds of data through them. For example, registered people will be entitled to upload photos, comments or other environmental information (e.g., light, ambient pressure, noise) through their personal devices—smartphones and tablets and mediated by the apps developed for this platform. On top of this, also crowd positioning and movement information will be collected for seasonal, daily and even real-time insight. This support of social is very useful for two main reasons. First, the correlation between human activities (e.g., bathing facilities and related seasonal phenomena) and the coastal data evolution can be analyzed and cross-referenced with the other instrumental data for enriched insight. Secondly, a number of ancillary services to people could be enabled, and fed, by this heterogeneous and multi-layered platform; for instance, sand granulometry, weather and storm-related variations in the coastal profile collected by meteo stations, seasonal/weekly/daily crowd presence information could constitute the raw data on top of which tourism guidance applications could be built. 
Table 2. Example of some of the coastal data to be managed in the designed Coastal Management system. A concise description of each data is given, along with its electronic format, nature of the data (e.g., numeric, vector) and spatio-temporal features.

\begin{tabular}{|c|c|c|c|}
\hline Data & Details & Format & Notes \\
\hline Waves & period, direction, height & record & $\begin{array}{l}\text { Numeric + vector, spot (pos), } \\
\text { continuous (time) }\end{array}$ \\
\hline Granulometry & various parameters on samples & record & $\begin{array}{l}\text { Numeric + vector, spot (pos), } \\
\text { spot/periodic (time) }\end{array}$ \\
\hline Pebble movement & $\begin{array}{l}\text { displacement per pebble vs. } \\
\text { previous position }\end{array}$ & record & $\begin{array}{l}\text { Vector, zone + spot (pos) } \\
\text { spot + delta (time) }\end{array}$ \\
\hline Pebble abrasion & size and weight changes per pebble & record & $\begin{array}{l}\text { Numeric + vector, zone (pos), } \\
\text { spot + delta (time) }\end{array}$ \\
\hline Topographic profile & $\begin{array}{l}\text { height from shoreline to first dune } \\
\text { on shore-orthogonal lines }\end{array}$ & record & Numeric, spot (pos), spot (time) \\
\hline Topographic shape & height profiles & shape & Shape file, zone (pos), spot (time) \\
\hline Maps & vector maps of specific zones & map & Vector pdf, zone (pos), spot (time) \\
\hline Map shapefile & specific studies & shape & shapefile, zone (pos), spot (time) \\
\hline Weather & $\begin{array}{l}\text { wind direction and } \\
\text { speed,temperature, rain }\end{array}$ & record & $\begin{array}{l}\text { Number + vector, spot (pos), } \\
\text { continuous (time) }\end{array}$ \\
\hline Coastline & photo mosaics, tables, polygons & $\begin{array}{l}\text { shape } \\
\text { record }\end{array}$ & $\begin{array}{l}\text { Numeric + images, zone(pos), } \\
\text { spot(time) }\end{array}$ \\
\hline LiDAR & Specific zones (year 2010) & asc & $\begin{array}{l}\text { Lidar format, zone (pos), } \\
\text { spot (time) }\end{array}$ \\
\hline
\end{tabular}

All the considered data are, directly or indirectly, georeferenced. Some data have spot positional attributes (e.g., wind direction in a certain measurement station) while other have zone positional information (e.g., maps or shapefiles relative to specific areas). Data are time-referenced too and typically they have a spot timing attribute, a time-stamp. Some data are collected in a way that makes them a continuous series of samples, usually periodic and relatively fast (minutes, hours). In these cases, data collection is typically automatic. At the opposite of the spectrum, some data are the result of manual measurements campaigns (e.g., pebble displacement/abrasion estimation) performed episodically, sometimes with a slow periodicity (days, weeks, months) or at random moments in time.

In order to cope with georeferenced and timestamped data, and with specific data formats, in an efficient and standard way, we chose to integrate a GIS (Geographical Information System) software into the overall CosMan system. Furthermore, in this way, the overall system can rely on existing, well-known, GIS functionalities without needing to re-implement them. The only concern adopting this approach is the compatibility, integrability and programmability of the GIS software module within the enterprise infrastructure of the overall CosMan system. In fact, our elaboration engine requires to seamlessly use and interact with the encompassed GIS software for implementing ad hoc algorithms.

The requirement of advanced programmability of our CosMan system derives from its complex requirements, which goes far beyond the mandatory collection and sharing of heterogeneous coastal data, which is complex in itself. On top of that, data elaboration, fusion, filtering, investigation, analytics as well as 3D elaboration and Augmented Virtuality implementation, will constitute crucial non-trivial macro-features of the overall system. Therefore, the core engine of our CosMan system needs to be programmable in languages and ecosystems that support modular development for reuse and productivity, powerful abstraction mechanisms, rich set of third party libraries, compatibility with existing code-bases and scalability in the deployment and management. 


\subsubsection{System Architecture}

Based on the requirements and features analyzed in the previous sub-section, we have defined the reference architecture of the CosMan system, which is summarized in Figure 6.

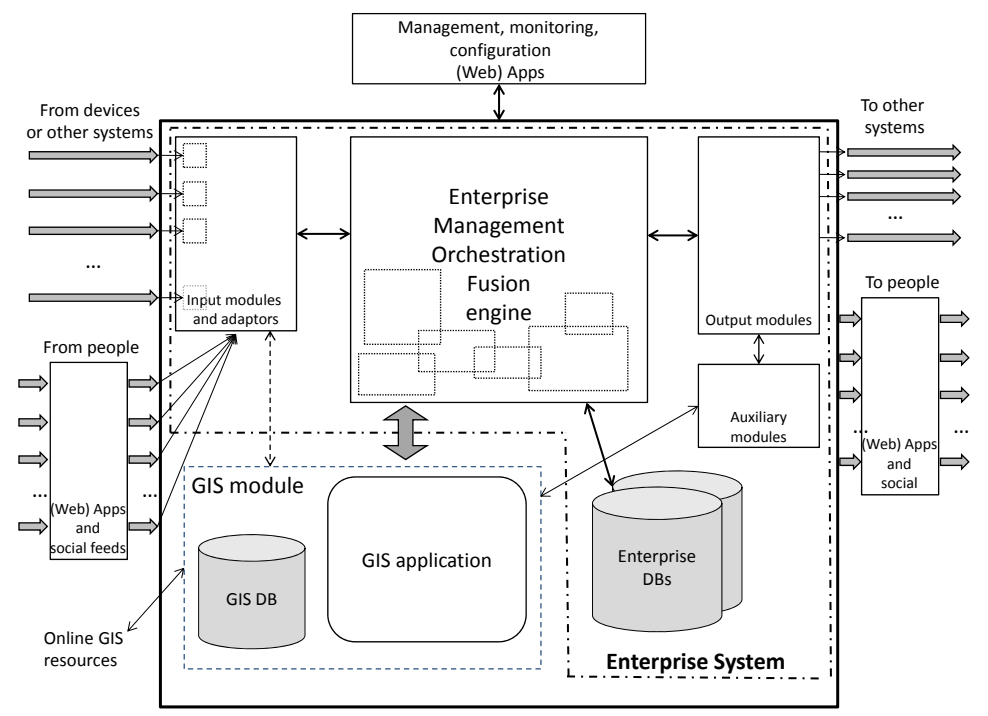

Figure 6. Overall architecture of the proposed Coastal Management System (CosMan) platform, highlighting the major modules and their relationships.

\subsubsection{Black-Box}

Specifically, from a black-box perspective, the CosMan system interfaces with three classes of users, which are defined by the kind of exchanged data: devices for data collection (input) and elaborated data consumption (output), people for informal data feed (input) and usage of the exposed services for professionals and citizens (output), and lastly towards the administrators of the system itself. First of all, the left side of the figure shows the input data fluxes. In the top-left, data from devices are indicated, for instance from measurement stations on the field or from workstations on which data were elaborated before the feeding to our system. Data are transferred towards specific webservices exposed by the CosMan system. Each data has its own webservice module, id (e.g., RESTful [91] URI (Uniform Resource Identifier) id) and available operations for data transfer and encoding. Webservices are the current most compatible, platform-agnostic interfacing between distributed interoperable systems in the web and are at the foundation of almost the totality of services that we consume nowadays in our online life [92]. Therefore, to promote flexibility and composability of our system with existing services and platforms, webservice interfacing is the most suitable choice. If we will need to support some latency-critical, real-time, streaming data fluxes for some data that we will need to manage in the future, we will probably adopt websocket technology (www.websocket.org), which is now standard within HTML5 specification, supported by almost every client platform and by our enterprise framework.

On the left-bottom side of Figure 6, the input channel from specific apps and/or web apps is shown. It relies on the same and, most of all, additional webservices to support the specific data coming from user applications (e.g., pictures, comments) and the corresponding interaction protocols. The opposite left side of the diagram shows the output links of the CosMan system. Similarly to the input side, we have provided both channels towards other devices/systems (top-right) and apps directly used by people (professional and citizens). In both cases, again, webservices are the first choice technology to support the output interaction for compatibility and generality in the Web 2.0 framework [93-95]. Webservices exposed to other devices allow to seamlessly insert the CosMan system within more articulated software architectures and exploit its offered services in a composable and modular way 
(Software as a Service approach or SaaS [94,96]). Therefore, the universal webservice language allows also an easy interfacing towards client applications, both native (apps) and web-based (web-apps), and third-party applications. On the top side of the diagram, the figure shows the input-output links from/to the management client applications, which allow for monitoring, managing, administering and configuring all the behaviors of the system. In addition, these links are now supported by webservices, but we also do not exclude the future support of proprietary software interconnections to address possible specific interactivity issues.

Data quality issues are managed as described in the following. First of all, social data feeds are treated as low-quality data and kept separated from the others provided by scientific-grade devices and sensors. Then, data that need manual intervention for the collection and/or insertion into the system (e.g., coarse sediment abrasion rate) are managed by client-side web-apps that allow the easy input and possible pre-filtering/pre-elaboration before acquisition into CosMan. Some data that are automatically collected but need human validation before usage and visualization (e.g., in a sensor network with possible anomalous spikes) are stored in a "pending" status and thus prevented from usage in data fusion and visualization. Data can then be validated by a human intervention and promoted to "valid" state. Finally, there are data that are collected and used automatically (e.g., from weather stations). Communication robustness in terms of delivery reliability and integrity are orthogonal to the described functionalities and are solved through well-known low-level mechanisms (e.g., buffering, sequencing, hashing).

\subsubsection{White-Box}

The internal of the system (white-box) exposes the macro sub-division in a GIS software (e.g., QGIS in our current prototype, www.qgis.org) and the Enterprise System, a Java Enterprise application [97]. QGIS, as other GIS softwares, can manage a huge number of georeferenced data and support a wide range of elaboration procedures on them, natively and as plugins. QGIS has Python and C++ APIs (Application Programming Interface) available, which allow for directly interacting with it from other programs in a very flexible and efficient fashion in order to extend its capabilities and exploit its functionalities. Our Java enterprise engine can directly communicate with QGIS through offloaded Python scripting as well as Java Native Interface (JNI) [98] technology towards C++ interface classes, which can exploit GIS internal API and services. Furthermore, QGIS can take advantage from auxiliary modules like MapServer (mapserver.org), indicated in the right-bottom of Figure 6, to ease the publishing of spatial data and interactive mapping applications to the web.

Java Enterprise edition technologies [97] allow for supporting a rich, flexible and modular programming model and scalable deployment possibilities through application servers and, possibly, also towards cloud resources. Modularity and scalability are pursued both at application-level and at deployment-level so that the system is ready to scale in terms of (a) number and kind of data/visualizations to be managed (application scalability); and (b) number and kind of hardware resources that are needed to support the computational and storage requirements over time (deployment scalability).

JAX-RS [99] library allows for supporting restful webservices effectively, being able to easily implement hierarchies of classes and data structures as to reuse and compose code for the different data feeds (input) and offered services (output). JAXB [100] library then allows to manage data format serialization towards JSON (JavaScript Object Notation), XML as well as binary encoding compatible with webservices in a standard way, where possible, and can be extended for very peculiar data, if needed. Therefore, data I/O towards/from the system flows through webservice interfaces that are very general and able to support both structured data (e.g., values, records of values, sequences of records, etc) directly through JSON encoding as well as binary data through base64 preliminary encoding. We have verified that this is enough for our reference data. The Object-Relationship-Mapping (ORM) capabilities of the Java Enterprise platform allow easy interfacing with data storages, both relational and non-relational, through entity classes and objects. This choice promotes flexibility 
because some new data and/or meta-data that will be managed in the future could need specific and diverse database layers, and possibly even changes in the database technologies over time. This way, the actual storage is shielded from the core logic of the enterprise application as stored data is represented by classes and objects.

The main functionalities for data aggregation, fusion and Augmented Virtuality services are implemented at the higher level—in the Enterprise, Management, Orchestration, Fusion Engine-in Java and mainly exposed internally through Enterprise Beans EBs [101]. This allows for promoting code reuse and, most of all, an efficient scalability of the offered services.

In fact, as it is hard to predict the exact computing power to run the system in a certain moment in time according to the specific set of data that it will manage, the platform was designed with elastic properties thanks to the adoption of (a) enterprise-class solutions compatible with application servers; (b) with the decoupling from the specific database technology and (c) with the possibility to migrate parts of the infrastructure into cloud services. In fact, computational requirements and cost will vary according to the set of data to be managed and their intensity (e.g., related to the number of collecting nodes for a particular datum, like weather stations). Developing the system for enterprise application servers (a) allows for seamlessly supporting the computational power scalability, and elasticity, through the addition of computing nodes and their orchestration, as well as fault tolerance and security features. Regarding (b) the adopted ORM abstraction layers will allow us to change the underlying database technology, even towards non-relational solutions if needed during the system growth, with minimal impact on the overall functionalities.

Algorithms can then be implemented directly in Java or in other languages like $\mathrm{C}++$, relying on JNI for exporting $\mathrm{C}++$ functionalities within the Java code. $\mathrm{C}++$ development is often required for efficiency reasons, and for easily integrating both third-party libraries and our internal code-bases on image elaboration, data fusion, 3D, mixed-reality, etc. As a cross-cutting topic, the system implements a security model which allows for having public and registered accesses for regulating the usage of the various input, output and management functions.

In conclusion, this kind of architecture allows for directly and effectively implementing a flexible and extensible data collection and fusion platform for coastal monitoring and for exposing Augmented Virtuality services for real-time and historical monitoring and investigation. Furthermore, its open standard architecture potentially enables to use the CosMan system as a component/service to exploit these data for implementing additional functionalities (e.g., to improve local weather forecasts applications) and value-added services (e.g., smart-environment applications like lifeguard/assistance spatio-temporal provisioning based on crowd status and evolution).

\subsection{Augmented Virtuality Visualization}

The last component in CosMan system is represented by data visualization. In this context, 3D imaging can be exploited to re-create a virtual representation of a coastal area that can be enriched with the direct and interactive visualization of the collected data as elaborated by the CosMan platform: this is exactly the so-called paradigm of Augmented Virtuality, where a virtual object is augmented with data collected directly from the real world. A simple example of the concept of Augmented Virtuality applied to coastal management can be seen in Figure 7, where a virtual portion of coast (in this case a satellite map of the area under study) is enriched with real data collected in situ (values of the water $\mathrm{pH})$.

Automated 3D visualization of terrain and cities has recently gained popularity. Following this trend, stereo vision can be integrated into the coast monitoring systems at various levels, as described in Sections 3.1 (UAVs) and 4.3 (in situ video acquisition systems). Using state-of-the-art equipment (stereo vision devices), eventually combined with high performance UAVs, significant image sets coming from multiple sources of acquisition (terrain and flight subsystems) can be overlapped together with a new $3 \mathrm{D}$ reconstructive approach, achieving a composite plan visualization with minimal user intervention, with the potential for extracting depth information and thus the means to assess volume directly. 
With the availability of 3D features (Depth o 3D Point Cloud), the application of object detection techniques, opportunely tuned for the 3D data, is then possible. Moreover, also the definition of the objects of interest can be settled by the end-user. The techniques for sea/land segmentation for on-site environmental monitoring can be brought to a new level, both using the color and depth information [102,103]. Moreover, other interesting objects can be detected and then tracked, especially for on-site surveillance purposes, whenever located on the beach or above the sea surface. The interest for these types of objects is that they can be moving objects (small ships, buoys, persons, vehicles, etc.) [104]. Lastly, also new methodologies of segmentation based on NN (Neural Networks) analysis can be investigated to characterize the status of the monitored scene [105] at a semantic level. These techniques could also be applied at a low level (in situ), both using the information available from remote sensed database and re-process at granular scale, in order to improve eventually also remote sensed data reliability. These new techniques are exactly the basic tools to build an efficient system for an evolute instrument of fruition of maritime data, independently from the end-user goals (monitoring or intelligent visualization), towards a more immersive way of data rendering for this specific context (Figure 8).

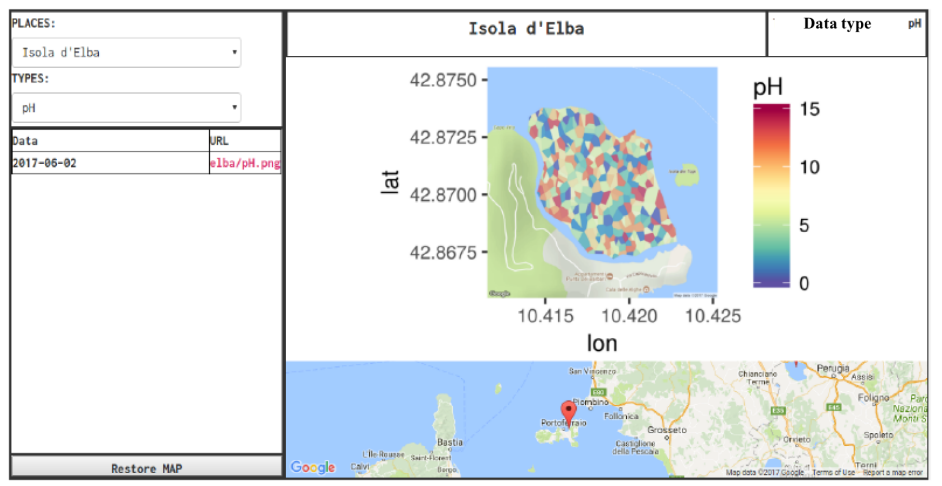

Figure 7. Example of Augmented Virtuality applied to coastal management where a virtual reconstruction of the coast (in this case a satellite map) is augmented with real data collected in situ.

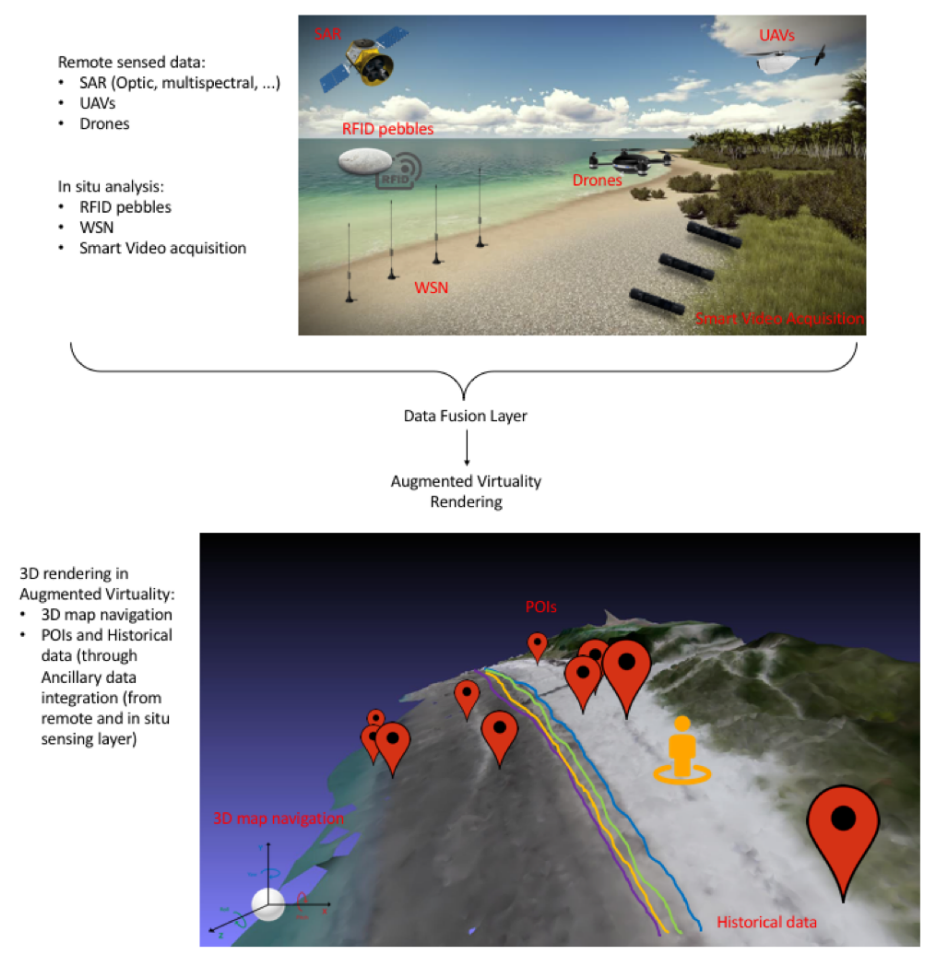

Figure 8. Example of aggregated system for maritime data fusion and fruition. 


\section{Conclusions}

In this paper, the architecture of a novel infrastructure for Coastal Management is presented and described. This infrastructure has been designed to integrate different monitoring sub-systems that concur to create heterogeneous datasets that can be analyzed to define coastal dynamics at the scale of the physiographic unit, helping public administrations to better face erosive processes. With this local approach, processing and interpretation of the data would be more immediate and the resulting observations may be used to make adequate decisions in all the aspects related to coastal management. Hints of increasing coastline retreat, the need for integration to beach fill interventions, and beach recovery after storms are just a few facets that can be improved or quickly dealt with using the presented approach. The infrastructure is provided with an innovative visualization tool based on the Augmented Virtuality, which allows not only the collected datasets to be viewed and analyzed interactively by scholars and researchers but also by common citizens and public administrations.

While the described architecture partially relies on existing or well-established technological solutions, the overall holistic approach represents a remarkable advancement with respect to existing systems. Indeed, in the proposed infrastructure, each sub-system cannot be seen as a separate unit, but it is only meaningful if integrated with all the other sub-systems through data fusion procedures. Moreover, the system also proposes a participative approach where citizens are allowed to become part of the data management and acquisition process by letting them freely access the collected information and cooperate to the data collection process. As crowdsourcing leads to validation issues, the data would undergo strict validation processes before being made available.

While the general framework of the proposed infrastructure has already been set up as a monitoring tool for the management of the coast of the Tuscany Region in Italy, and several sub-systems are already operative, the deployment of the whole infrastructure will require a long-term work due to the will to integrate a wide range of different technical solutions. This work will be carried out by the so-called Team COSTE, a joint group set up by the Universities of Pisa, Siena and Florence, all of them located in Tuscany, Italy, in order to put together the wide range of knowledge required to implement the holistic approach that stands at the base of the whole architecture.

Author Contributions: S.B. conceived the overall software architecture. A.M. developed the concept of Augmented Virtuality applied to the analysis of coastal processes. A.P. developed the WSN and RFID tracing system prototypes and conceived all the applications of these technologies for coastal monitoring writing the related section as well as the section about the holistic approach. C.Z. wrote all the section regarding video monitoring. D.B and G.S. wrote all the introductory sections and defined the application scenario in terms of physiographic unit. A.Ca. and R.C. developed the described AUV applications and wrote the corresponding section. A.Ci., F.C. and S.M. wrote the section about Proximal and Distal Remote Sensing. The overall structure of the paper has been conceived by A.P. and D.B.

Conflicts of Interest: The authors declare no conflict of interest.

\section{References}

1. Bird, E.C.F. Coastline Changes; Wiley \& Sons: Hoboken, NJ, USA, 1985.

2. Masselink, G.; Hughes, M.G.; Knight, J. Introduction to Coastal Processes and Geomorphology; Routledge: Abingdon-on-Thames, UK, 2014.

3. Bertoni, D.; Sarti, G. On the profile evolution of three artificial pebble beaches at Marina di Pisa, Italy. Geomorphology 2011, 130, 244-254.

4. Bruun, P. Sea-level rise as a cause of shore erosion. J. Waterw. Harb. Div. 1962, 88, 117-132.

5. Leatherman, S.P.; Zhang, K.; Douglas, B.C. Sea level rise shown to drive coastal erosion. Eos 2000, 81, 55-57.

6. Nordstrom, K.F.; Jackson, N.L.; Roman, C.T. Facilitating landform migration by removing shore protection structures: Opportunities and constraints. Environ. Sci. Policy 2016, 66, 217-226.

7. García-Mora, M.R.; Gallego-Fernández, B.; Williams, A.T.; García-Novo, F. A coastal dune vulnerability classification. A case study of the SW Iberian Peninsula. J. Coast. Res. 2001, 17, 802-811. 
8. Alquini, F.; Bertoni, D.; Sarti, G.; Ciccarelli, D.; Pozzebon, A.; Melo Júnior, J.C.F.; Vieira, C.V. Vulnerability assessment of a coastal dune system at São Francisco do Sul Island (Santa Catarina, Brazil). IOP Conf. Ser. Earth Environ. Sci. 2016, 44, 052028.

9. Islam, M.A.; Mitra, D.; Dewan, A.; Akhter, S.H. Coastal multi-hazard vulnerability assessment along the Ganges deltaic coast of Bangladesh-A geospatial approach. Ocean Coast. Manag. 2016, 127, 1-15.

10. Jangir, B.; Satyanarayana, A.N.V.; Swati, S.; Jayaram, C.; Chowdary, V.M.; Dadhwal, V.K. Delineation of spatio-temporal changes of shoreline and geomorphological features of Odisha coast of India using remote sensing and GIS techniques. Nat. Hazards 2016, 82, 1437-1455.

11. Suhura, S.; Nithyapriya, B.; Revanth Reddy, L.; Philipose, N.; Manisha, M.; Dwarakish, G.S. Coastal Land Use/Land Cover and Shoreline Studies for Dakshina Kannada Coast, Karnataka, India. Water Resour. Manag. 2018, 78, 269-281.

12. French, P.W. Coastal Defences: Processes, Problems and Solutions; Routledge: Abingdon-on-Thames, UK, 2001.

13. Bertoni, D.; Alquini, F.; Bini, M.; Ciccarelli, D.; Giaccari, R.; Pozzebon, A.; Ribolini, A.; Sarti, G. A technical solution to assess multiple data collection on beach dunes: The pilot site of migliarino San Rossore regional park (Tuscany, Italy). Atti della Societá Toscana di Scienze Naturali Memorie Serie A 2014, 121, 5-12.

14. ASFPM Foundation. Holistic Coasts: A Summary Report Based on the 4th Assembly of the Gilbert F; White National Flood Policy Forum Arlington: Arlington, VA, USA, 2013.

15. Best, M.M.; Favali, P.; Beranzoli, L.; Cannat, M.; Cagatay, M.N.; Danobeitia, J.J.; Grant, F. European multidisciplinary seafloor and water-column observatory (EMSO): Power and Internet to European waters. In Proceedings of the 2014 Oceans-St. John's, St. John's, NL, Canada, 14-19 September 2014; pp. 1-7.

16. Iannaccone, G.; Guardato, S.; Vassallo, M.; Elia, L.; Beranzoli, L. A new multidisciplinary marine monitoring system for the surveillance of volcanic and seismic areas. Seismol. Res. Lett. 2009, 80, 203-213.

17. Bio, A.; Bastos, L.; Granja, H.; Pinho, J.L.; Goncalves, J.A.; Henriques, R.; Rodrigues, D. Methods for coastal monitoring and erosion risk assessment: Two Portuguese case studies. Revista de Gestao Costeira Integrada 2015, 15, 47-63.

18. Archetti, R.; Zanuttigh, B. Integrated monitoring of the hydro-morphodynamics of a beach protected by low crested detached breakwaters. Coast. Eng. 2010, 57, 879-891.

19. Ciampalini, A.; Consoloni, I.; Salvatici, T.; Di Traglia, F.; Fidolini, F.; Sarti, G.; Moretti, S. Characterization of coastal environment by means of hyper- and multispectral techniques. Appl. Geogr. 2015, 57, 120-132.

20. Nolet, C.; Poortinga, A.; Roosjen, P.; Bartholomeus, H.; Ruessink, G. Measuring and modeling the effect of surface moisture on the spectral reflectance of coastal beach sands. PLOS ONE 2014, 9, e112151.

21. Shi, Z.; Huang, M.X. Evaluating reclamation levels of coastal saline soil using laboratory hyperspectral data. Eurasian Soil Sci. 2007, 40, 1095-1101.

22. Gigli, G.; Frodella, W.; Mugnai, F.; Tapete, D.; Cigna, F.; Fanti, R.; Intrieri, E.; Lombardi, L. Instability mechanisms affecting cultural heritage sites in the Maltese Archipelago. Nat. Hazards Earth Syst. Sci. 2012, 12, 1883-1903.

23. Intrieri, E.; Di Traglia, F.; Del Ventisette, C.; Gigli, G.; Mugnai, F.; Luzi, G.; Casagli, N. Flank instability of Stromboli volcano (Aeolian Islands, Southern Italy): Intergration of GB-InSAR and geomorphological observations. Geomorphology 2013, 201, 60-69.

24. Bardi, F.; Raspini, F.; Ciampalini, A.; Kristensen, L.; Rouyet, L.; Lauknes, T.R.; Frauenfelder, R.; Casagli, N. Space-borne and ground-based InSAR data integration: The Åknes test site. Remote Sens. 2016, 8, 237.

25. Casagli, N.; Frodella, W.; Morelli, S.; Tofani, V.; Ciampalini, A.; Intrieri, E.; Raspini, F.; Rossi, G.; Tanteri, L.; $\mathrm{Lu}, \mathrm{P}$. Spaceborne, UAV and ground-based remote sensing techniques for landslide mapping, monitoring and early warning. Geoenviron. Disasters 2016, 4, 9.

26. Tanteri, L.; Rossi, G.; Tofani, V.; Vannocci, P.; Moretti, S.; Casagli, N. Multitemporal UAV survey for mass movement detection and monitoring. In Proceedings of the Workshop on World Landslide Forum, Ljubljana, Slovenia, 29 May-2 June 2017; pp. 153-161.

27. Small, C.; Steckler, M.; Seeber, L.; Akhter, S.H.; Goodbred, S., Jr.; Mia, B.; Imam, B. Spectroscopy of sediments in the GangeseBrahmaputra delta: Spectral effects of moisture, grain size and lithology. Remote Sens. Environ. 2009, 113, 342-361.

28. Solari, L.; Ciampalini, A.; Raspini, F.; Bianchini, S.; Moretti, S. PSInSAR analysis in the Pisa urban area (Italy): A case study of subsidence related to stratigraphical factors and urbanization. Remote Sens. 2016, 8, 120.

29. Holman, R.; Haller, M.C. Remote sensing of the nearshore. Annu. Rev. Mar. Sci. 2013, 5, 95-113. 
30. Liu, Y.; Islam, M.A.; Gao, J. Quantification of shallow water quality parameters by means of remote sensing. Prog. Phys. Geogr. 2003, 27, 24-43.

31. Power, H.E.; Holman, R.A.; Baldock, T.E. Swash zone boundary conditions derived from optical remote sensing of swash zone flow patterns. J. Geophys. Res. 2011, 116, C06007.

32. Teodoro, A.; Pais-Barbosa, J.; Goncalves, H.; Veloso-Gomes, F.; Taveira-Pinto, F. Identification of beach hydromorphological patterns/forms through image classification techniques applied to remotely sensed data. Int. J. Remote Sens. 2011, 32, 7399-7422.

33. Teodoro, A.; Pais-Barbosa, J.; Veloso-Gomes, F.; Taveire-Pinto, F. Evolution of beach hydromorphological behaviour and classification using image classification techniques. J. Coast. Res. 2009, 56, 1607-1611.

34. Xu, J.; Zhang, Z.; Zhao, X.; Wen, Q.; Zuo, L.; Wang, X.; Yi, L. Spatial and temporal variations of coastlines in northern China. J. Geogr. Sci. 2014, 24, 18-32.

35. Doxaran, D.; Froidenfond, J.M.; Lavander, S.; Castaing, P. Spectral signature of highly turbid waters application with SPOT data to quantify suspended particulate matter concentrations. Remote Sens. Environ. 2002, 81, 149-161.

36. Min, J.E.; Ryu, J.H.; Lee, S.; Son, S. Monitoring of suspended sediment variation using Landsat and MODIS in the Seamangeum costal area of Korea. Mar. Pollut. Bull. 2012, 64, 382-390.

37. Tang, D.L.; Kawamura, H.; Doan, H.; Takahashi, W. Remote sensing oceanography of a harmful algal bloom off the coast of southeastern Vietnam. J. Geophys. Res. Ocean 2016, 109, C03014.

38. Ryu, J.H.; Won, J.S.; Min, K.D. Waterline extraction from Landsat TM data in a tidal flat. A case study in Gomso Bay, Korea. Remote Sens. Environ. 2002, 83, 442-456.

39. Kuenzer, C.; van Beijma, S.; Gessner, U.; Dech, S. Land surface and environmental challeges of the Niger Delta, Africa: Remote sensing-based analyses spanning three decades (1986-2013). Appl. Geogr. 2014, 53, 354-368.

40. Gosh, M.K.; Kumar, L.; Roy, C. Monitoring the coastline change of Hatia Island in Bangladesh using remote sensing techniques. ISPRS J. Photogramm. Remote Sens. 2015, 101, 137-144.

41. Yang, H.; Lee, D.G.; Kim, T.H.; Sumantyo, J.T.S.; Kim, J.H. Semi-automatic coastline extraction method using Synthetic Aperture Radar images. In Proceedings of the 16th International Conference on Advanced Communication Technology, Pyeongchang, Korea, 16-19 February 2014; pp. 678-681.

42. Baselice, F.; Ferraioli, G. Unsupervised coastal line extraction from SAR images. IEEE Geosci. Remote Sens. Lett. 2013, 10, 1350-1354.

43. Fruneau, B.; Achache, L.; Delacourt, C. Observation and modeling of the Saint-Etienne-de-Tine'e Landslide using SAR interferometry. Tectonophysics 1996, 265, 181-190.

44. Singhroy, V.; Mattar, K.E.; Gray, A.L. Landslide characterisation in Canada using interferometric SAR and combined SAR and TM images. Adv. Space Res. 1998, 21, 465-476.

45. Ferretti, A.; Prati, C.; Rocca, F. Permanent Scatterers in SAR interferometry. IEEE Trans. Geosci. Remote Sens. 2001, 39, 8-20.

46. Ferretti, A.; Fumagalli, A.; Novali, F.; Prati, C.; Rocca, F.; Rucci, A. A new algorithm for processing interferometric data-stacks: SqueeSAR. IEEE Trans. Geosci. Remote Sens. 2011, 49, 3460-3470.

47. Lanari, R.; Mora, O.; Manunta, M.; Mallorqui, J.J.; Berardino, P.; Sansosti, E. A small baseline approach for investigating deformation on full resolution differential SAR interferograms. IEEE Trans. Geosci. Remote Sens. 2004, 42, 1377-1386.

48. Hooper, A.; Zebker, H.A.; Segall, P.; Kampes, B. A new method for measuring deformation on volcanoes and other natural terrains using InSAR persistent scatterers. Geophys. Res. Lett. 2004, 31, doi:10.1029/2004GL021737.

49. Sun, H.; Zhang, Q.; Zhao, C.; Yang, C.; Sun, Q.; Chen, W. Monitoring land subsidence in the southern part of the lower Liahoe plain, China with a multi-track PS-InSAR technique. Remote Sens. Environ. 2017, 188, $73-84$.

50. Notti, D.; Galve, J.P.; Mateos, R.M.; Montserrat, O.; Lamas-Fernandez, F.; Fernandez-Chacon, F.; Roldan-Garcia, F.J.; Perez-Pena, J.V.; Crosetto, M.; Azanon, J.M. Human-induced coastal landslide reactivation. Monitoring by PSInSAR techniques and urban damage survey (SE Spain). Landslides 2015, 12, 1007-1014.

51. Mancini, F.; Dubbini, M.; Gattelli, M.; Stecchi, F.; Fabbri, S.; Gabbianelli, G. Using Unmanned Aerial Vehicles (UAV) for High-Resolution Reconstruction of Topography: The Structure from Motion Approach on Coastal Environments. Remote Sens. 2013, 5, 6880-6898. 
52. Bell, M. Shallow Water Bathymetry Using the REMUS 100 Autonomous Underwater Vehicle (No. DSTO-TR-2916); Defence Science and Technology Organisation Edinburgh (Australia) Maritime Operations Division: Edinburgh, Australia, 2013.

53. Shcherbina, A.Y.; Gawarkiewicz, G.G.; Linder, C.A.; Thorrold, S. Mapping bathymetric and hydrographic features of Glover's Reef, Belize, with a REMUS autonomous underwater vehicle. Limnol. Oceanogr. 2008, 53, 2264-2272.

54. Hagen, P.E.; Storkersen, N.; Marthinsen, B.E.; Sten, G.; Vestgard, K. Rapid environmental assessment with autonomous underwater vehicles-Examples from HUGIN operations. J. Mar. Syst. 2008, 69, 137-145.

55. Antonelli, G. Underwater robots; Springer International Publishing: Berlin/Heidelberg, Germany, 2014.

56. Leonard, J.J.; Bahr, A. Autonomous underwater vehicle navigation. In Springer Handbook of Ocean Engineering; Dhanak, M.R., Xiros, N.I., Eds.; Springer International Publishing: Cham, Switzerland, 2016; pp. 341-358.

57. Kinsey, J.C.; Eustice, R.M.; Whitcomb, L.L. A survey of underwater vehicle navigation: Recent advances and new challenges. In Proceedings of the IFAC Conference of Manoeuvering and Control of Marine Craft, Lisbon, Portugal, 20-22 September 2006; Volume 88, pp. 1-12.

58. Allotta, B.; Caiti, A.; Costanzi, R.; Fanelli, F.; Fenucci, D.; Meli, E.; Ridolfi, A. A new AUV navigation system exploiting unscented Kalman filter. Ocean Eng. 2016, 113, 121-132.

59. Allotta, B.; Bartolini, F.; Caiti, A.; Costanzi, R.; Di Corato, F.; Fenucci, D.; Gelli, J.; Guerrini, P.; Monni, N.; Munaf, A.; et al. Typhoon at commsnet13: Experimental experience on auv navigation and localization. Annu. Rev. Control 2015, 40, 157-171.

60. Di Corato, F.; Fenucci, D.; Caiti, A.; Costanzi, R.; Monni, N.; Pugi, L.; Ridolfi, A.; Allotta, B. Toward underwater acoustic-based simultaneous localization and mapping. Experimental results with the Typhoon AUV at CommsNet13 sea trial. In Proceedings of the 2014 Oceans-St. John's, St. John's, NL, Canada, 14-19 September 2014; pp. 1-7.

61. Allotta, B.; Caiti, A.; Costanzi, R.; Fanelli, F.; Meli, E.; Ridolfi, A. Development and Online Validation of an UKF-based Navigation Algorithm for AUVs. IFAC-PapersOnLine 2015, 49, 69-74.

62. Duane, D.B. Tracing Sand Movement in the Littoral Zone: Progress in the Radioisotopic Sand Tracer (RIST) Study, July 1968-February 1969 (No. CERC-MISC); Coastal Engineering Research Center: Vicksburg, MS, USA, 1970.

63. Chapman, D.M.; Smith, A.W. Methodology of a large scale sand tracer experiment. In Proceedings of the Third Australian Conference on Coastal and Ocean Engineering, 1977: The Coast, the Ocean and Man, Melbourne, Australia, 18-21 April 1977; p. 181.

64. Nicholls, R.J.; Webber, N.B. Aluminum pebble tracer experiments on Hurst Castle Spit. In Proceedings of the Coastal Sediments, New Orleans, LA, USA, 12-13 May 1987; pp. 1563-1577.

65. Bray, M.J.; Workman, M.; Smith, J.; Pope, D. Field measurements of shingle transport using electronic tracers. In Proceedings of the 31st MAFF Conference of River and Coastal Engineers, Keele, UK, 3-5 July 1996; p. 104.

66. Yasso, W.E. Formulation and use of fluorescent tracer coatings in sediment transport studies. Sedimentology 1966, 6, 287-301.

67. Hassan, M.A.; Schick, A.P.; Laronne, J.B. The recovery of flood-dispersed coarse sediment particles, a three-dimensional magnetic tracing method. Catena Suppl. 1984, 5, 153-162.

68. Ergenzinger, P.; De Jong, C. Perspectives on Bed Load Measurement; IAHS Publication: London, UK, 2003; pp. 113-125.

69. Benelli, G.; Pozzebon, A.; Raguseo, G.; Bertoni, D.; Sarti, G. An RFID Based System for the Underwater Tracking of Pebbles on Artificial Coarse Beaches. In Proceedings of the 2009 Third International Conference on Sensor Technologies and Applications, Athens/Glyfada, Greece, 18-23 June 2009; pp. 294-299.

70. Benelli, G.; Pozzebon, A.G.; Bertoni, D.; Sarti, G. An RFID-Based Toolbox for the Study of Under- and Outside-Water Movement of Pebbles on Coarse-Grained Beaches. IEEE J. Sel. Top. Appl. Earth Obs. Remote Sens. 2012, 5, 1474-1482.

71. Benelli, G.; Panzardi, E.; Pozzebon, A.G.; Bertoni, D.; Sarti, G. An analysis on the use of LF RFID for the tracking of different typologies of pebbles on beaches. In Proceedings of the 2011 IEEE International Conference on RFID-Technologies and Applications, Sitges, Spain, 15-16 September 2011; pp. 426-431.

72. Corke, P.; Wark, T.; Jurdak, R.; Hu, W.; Valencia, P.; Moore, D. Environmental wireless sensor networks. Proc. IEEE 2010, 98, 1903-1917.

73. Albaladejo, C.; Sanchez, P.; Iborra, A.; Soto, F.; Lopez, J.A.; Torres, R. Wireless sensor networks for oceanographic monitoring: A systematic review. Sensors 2010, 10, 6948-6968. 
74. Xu, G.; Shen, W.; Wang, X. Applications of wireless sensor networks in marine environment monitoring: A survey. Sensors 2014, 14, 16932-16954.

75. Heidemann, J.; Stojanovic, M.; Zorzi, M. Underwater sensor networks: applications, advances and challenges. Philos. Trans. R. Soc. A Math. Phys. Eng. Sci. 2012, 370, 158-175.

76. Pozzebon, A.; Bove, C.; Cappelli, I.; Alquini, F.; Bertoni, D.; Sarti, G. Heterogeneous Wireless Sensor Network for Real Time Remote Monitoring of Sand Dynamics on Coastal Dunes. IOP Conf. Ser. Earth Environ. Sci. 2016, 44, 042030.

77. Lippmann, T.C.; Holman, R.A. The spatial and temporal variability of sand bar morphology. J. Geophys. Res. 1990, 95, 11575-11590.

78. Kroon, A.; Aarninkhof, S.G.J.; Archetti, R.; Armaroli, C.; Gonzalez, M.; Medri, S.; Osorio, A.; Aagaard, T.; Davidson, M.A.; Holman, R.A.; et al. Application of remote sensing video systems for coastline management problems. Coast. Eng. 2007, 54, 493-505.

79. Turner, I.L.; Anderson, D.J. Web-based and 'real-time' beach management system. Coast. Eng. 2007, 54, 555-565.

80. Brignone, M.; Schiaffino, C.F.; Isla, F.I.; Ferrari, M. A system for beach video-monitoring: Beachkeeper plus. Comput. Geosci. 2012, 49, 53-61.

81. Trucco, E.; Verri, A. Introductory Techniques for 3-D Computer Vision; Prentice Hall, Inc.: Upper Saddle River, NJ, USA, 1998.

82. Taborda, R.; Silva, A. COSMOS: A lightweight coastal video monitoring system. Comput. Geosci. 2012, 49, 248-255.

83. Chickadel, C.C.; Holman, R.A.; Freilich, M. An optical technique for the measurement of long-shore currents. J. Geophys. Res. Oceans 2003, 108, doi:10.1029/2003JC001774.

84. Boak, E.H.; Turner, I.L. Shoreline definition and detection: A review. J. Coast. Res. 2005, 21, 688-703.

85. Holland, K.T.; Vinzon, S.B.; Calliari, L.J. A field study of coastal dynamics on a muddy coast offshore of Cassinobeach, Brazil. Cont. Shelf Res. 2009, 29, 503-514.

86. Short, A.D.; Trembanis, A.C. Decadal scale patterns in beach oscillation and rotation Narrabeen Beach, Australia-Time series, PCA and wavelet analysis. J. Coast. Res. 2004, 20, 523-532.

87. Davidson, M.; Van Koningsveld, M.; de Kruif, A.; Rawson, J.; Holman, R.; Lamberti, A.; Medina, R.; Kroon, A.; Aarninkhof, S. The CoastView project: Developing video-derived Coastal State Indicators in support of coastal zone management. Coast. Eng. 2007, 54, 463-475.

88. Lucas, B.D.; Kanade, T. An Iterative Image Registration Technique with an Application to Stereo Vision. In Proceedings of the 7th international joint conference on Artificial intelligence, Vancouver, BC, Canada, 24-28 August 1981; pp. 674-679.

89. Rusu, R.B.; Cousins, S. 3D is here: Point cloud library (PCL). In Proceedings of the IEEE International Conference on Robotics and automation (ICRA), Shanghai, China, 9-13 May 2011; pp. 1-4.

90. Hirschmuller, H. Stereo processing by semiglobal matching and mutual information. IEEE Trans. Pattern Anal. Mach. Intell. 2008, 30, 328-341.

91. Fielding, R.T. Architectural Styles and the Design of Network-Based Software Architectures. Ph.D. Thesis, University of California, Irvine, CA, USA, 2000.

92. Adamczyk, P.; Smith, P.; Johnson, R.; Hafiz, M. REST and Web Services: In Theory and in Practice. In REST: From Research to Practice; Springer: Berlin/Heidelberg, Germany, 2011.

93. Web 2.0 and Service Oriented Architectures (SOA). Available online: https://en.wikipedia.org/wiki/Web_2. 0 (accessed on 14 February 2018).

94. O'Reilly, T. What Is Web 2.0 Design Patterns and Business Models for the Next Generation of Software. 2005. Available online: http:/ /www.oreilly.com/pub/a/web2/archive/what-is-web-20.html (accessed on 14 February 2018).

95. O’Reilly, T.; Battelle, J. Web Squared: Web 2.0 Five Years On. Web 2.0 Summit. San Francisco, CA. 2009. Available online: https://conferences.oreilly.com/web2summit/web2009/public/schedule/detail/10194 (accessed on 14 February 2018).

96. Software as a Service (SaaS). Available online: https://en.wikipedia.org/wiki/Software_as_a_service (accessed on 14 February 2018).

97. Java Enterprise Edition (EE). Available online: http://www.oracle.com/technetwork/java/javaee/ overview/index.html (accessed on 10 March 2018) 
98. Oracle Documentation. Java Native Interface (JNI). Available online: https://docs.oracle.com/javase/8/ docs/technotes/guides/jni/c (accessed on 14 February 2018).

99. Oracle Documentation. Building RESTful Web Services with JAX-RS. Available online: https:// docs.oracle. $\mathrm{com} /$ javaee/7/tutorial/jaxrs.htm (accessed on 14 February 2018).

100. Oracle Documentation. Java Architecture for XML Binding (JAXB). Available online: https:/ / docs.oracle. $\mathrm{com} /$ javaee/7/tutorial/jaxrs-advanced007.htm (accessed on 14 February 2018).

101. Oracle Documentation. Enterprise Beans. Available online: https://docs.oracle.com/javaee/7/tutorial/ partentbeans.htm\#BNBLR (accessed on 14 February 2018).

102. Holz, D.; Holzer, S.; Rusu, R.B.; Behnke, S. Real-time plane segmentation using RGB-D cameras. In Robot Soccer World Cup; Springer: Berlin/Heidelberg, Germany, 2011; pp. 306-317.

103. Schnabel, R.; Wahl, R.; Klein, R. Efficient RANSAC for point-cloud shape detection. Comput. Graph. Forum 2007, 26, 214-226.

104. Kao, J.Y.; Tian, D.; Mansour, H.; Vetro, A.; Ortega, A. Moving object segmentation using depth and optical flow in car driving sequences. In Proceedings of the 2016 IEEE International Conference on Image Processing (ICIP), Phoenix, AZ, USA, 25-28 September 2016; pp. 11-15.

105. Lin, H.; Shi, Z.; Zou, Z. Maritime Semantic Labeling of Optical Remote Sensing Images with Multi-Scale Fully Convolutional Network. Remote Sens. 2017, 9, 480.

(c) 2018 by the authors. Licensee MDPI, Basel, Switzerland. This article is an open access article distributed under the terms and conditions of the Creative Commons Attribution (CC BY) license (http://creativecommons.org/licenses/by/4.0/). 